\title{
Green synthesis of AgNP-ligand complexes and their toxicological effects on Nilaparvata lugens
}

\author{
Hatem Fouad ${ }^{1,2^{*}}$ (D) Guiying Yang ${ }^{1}$, Ahmed A. El-Sayed ${ }^{3}$, Guofeng Mao ${ }^{1}$, Diab Khalafallah ${ }^{4}$, Mahmoud Saad ${ }^{2}$,
} Hassan Ga'al', Ezzeldin Ibrahim ${ }^{5}$ and Jianchu Mo ${ }^{1 *}$

\begin{abstract}
Background: Despite developments in nanotechnology for use in the pharmaceutical field, there is still a need for implementation of this technology in agrochemistry. In this study, silver nanoparticles (AgNPs) were successfully prepared by a facile and an eco-friendly route using two different ligands, $2^{\prime}$-amino-1, $1^{\prime}: 4^{\prime}, 1^{\prime \prime}$-terphenyl-3,3",5,5'tetracarboxylic acid $\left(\mathrm{H}_{4} \mathrm{~L}\right)$ and 1,3,6,8-tetrakis ( $p$-benzoic acid)-pyrene (TBAPy), as reducing agents. The physiochemical properties of the as-obtained AgNPs were characterized by scanning electron microscopy (SEM), energy-dispersive X-ray (EDX), X-ray diffraction (XRD) and transmission electron microscopy (TEM). The toxicity of $\mathrm{H}_{4} \mathrm{~L}$-AgNP and TBAPyAgNP against the brown planthopper (BPH, Nilaparvata lugens) was also measured.
\end{abstract}

Results: SEM and TEM analyses demonstrated the formation of quasi-spherical AgNP structures in the presence of $\mathrm{H}_{4} \mathrm{~L}$ and TBAPy. Insecticidal assays showed that TBAPy is less effective against N. Iugens, with a median lethal concentration $\left(\mathrm{LC}_{50}\right.$ ) of $810 \mathrm{mg} / \mathrm{L}$, while the toxicity of $\mathrm{H}_{4} \mathrm{~L}$ increased and their $\mathrm{LC}_{50}$ reached $786 \mathrm{mg} / \mathrm{L} 168 \mathrm{~h}$ posttreatment at a high concentration of $2000 \mathrm{mg} / \mathrm{L}$. $\mathrm{H}_{4} \mathrm{~L}-\mathrm{AgNPs}$ were also highly toxic at a low concentration of $20 \mathrm{mg} / \mathrm{L}$, with $\mathrm{LC}_{50}=\sim 3.9 \mathrm{mg} / \mathrm{L} 168 \mathrm{~h}$ posttreatment, while TBAPy-AgNPs exhibited less toxicity at the same concentration, with $\mathrm{LC}_{50}=\sim 4.6 \mathrm{mg} / \mathrm{L}$.

Conclusions: These results suggest that the synthesized AgNPs using the two ligands may be a safe and cheaper method compared with chemical insecticides for protection of rice plants from pests and has potential as an effective insecticide in the N. lugens pest management program.

Keywords: Nanotechnology, Organic ligands, Silver nanoparticles, Insecticidal effect, Nilaparvata lugens

*Correspondence: dr_hatem@zju.edu.cn; mojianchu@zju.edu.cn

${ }^{1}$ Ministry of Agriculture, Key Laboratory of Molecular Biology of Crop

Pathogens and Insect Pests, Key Laboratory of Biology of Crop Pathogens and Insects of Zhejiang Province, Institute of Insect Sciences, College of Agriculture and Biotechnology, Zhejiang University, Yuhangtang Road 866, Hangzhou, Zhejiang 310058, People's Republic of China

Full list of author information is available at the end of the article

\section{Background}

Nanotechnology has been explored to determine various physical and chemical ways to use nanosized silver (Ag) particles [1,2]. Noble metal nanoparticles (NPs) are widely used in electrochemical, electrodiagnostic, and bioelectrochemical applications because of their significant electroreactant activity due to their relatively high surface-area-to-volume ratio and interface-subjugated properties $[3,4]$. The medical use of NPs is attracting vast interest because of their low toxicity in different nontarget organs or organisms [5, 6]. Noble metal NPs (i.e., Ag, $\mathrm{Pt}, \mathrm{Au}$, and $\mathrm{Pd}$ ) are studied due to their low toxicity and original author(s) and the source, provide a link to the Creative Commons licence, and indicate if changes were made. The images or other third party material in this article are included in the article's Creative Commons licence, unless indicated otherwise in a credit line to the material. If material is not included in the article's Creative Commons licence and your intended use is not permitted by statutory regulation or exceeds the permitted use, you will need to obtain permission directly from the copyright holder. To view a copy of this licence, visit http://creativecommons.org/licenses/by/4.0/. The Creative Commons Public Domain Dedication waiver (http://creativeco mmons.org/publicdomain/zero/1.0/) applies to the data made available in this article, unless otherwise stated in a credit line to the data. 
low risk on the environment $[7,8]$. In particular, AgNPs have attracted great attention in the field of biology because of their exceptional and tunable surface plasmon resonance (SPR) $[9,10]$. Therefore, AgNPs have promising potential in bioscience, originating from their low ecotoxicological characterization $[11,12]$.

The brown planthopper (BPH) Nilaparvata lugens (Stål; Homoptera: Delphacidae) is an economically significant insect pest of rice plants in Asia [13]. BPH is distributed throughout many countries, such as Australia, China, Bangladesh, Cambodia, Fiji, India, Indonesia, and Japan. BPH causes damage to rice plants directly through feeding, and the plants turn yellow and rapidly dry up; this condition is called "hopper burn." In addition, BPH causes extensive harm to rice plants by transmitting two viruses, rice ragged stunt virus and rice grassy stunt virus [14]. Because of its high adaptive ability to changing social practices, high reproductive potential, and long-distance migrating capability, insecticides are essential and applied widely to control this monophagous insect throughout Asia [15]. However, the extensive use of insecticides to control this pest over many years has led to resistance to most of classes of chemical insecticides (organochlorines, organophosphates, carbamates, and pyrethroids). In addition, BPH has distinct biological and behavioral attributes, for example, short up-growth time, high fertility, and dispersal ability [16-18]. The increase in insects resistant to chemical insecticides and toxicity concerns have motivated researchers toward the development of new insecticides based on AgNPs [11, 19, 20]. The organic ligand 2'-amino-1,1':4',1"'terphenyl-3,3",5,5"tetracarboxylic acid $\left(\mathrm{H}_{4} \mathrm{~L}\right)$ was first reported by Bharadwaj et al. [21] to synthesize non-interpenetrated porous metal-organic frameworks (PMOFs) containing paddle-wheel secondary bonding units (SBUs). Pyrene and its derivatives have been widely investigated as fluorescence probes in many applications. For example, pyrene-labeled oligonucleotides have been used to study DNA hybridization [22, 23], and pyrene-labeled lipids have been developed to examine the depth-dependent quenching of fluorescence in lipid bilayers [24-26]. Recently, pyrene was used as a ligand to synthesize a mesoporous MOF and a catalytically active iridium pincer complex [27, 28].

Exploring an effective and versatile synthesis route to fabricate noble metal NPs without any toxic chemicals is still a challenge but desirable. In this study, we developed an efficient liquid-phase reduction method to produce a Ag colloidal suspension using two organic compounds in the presence of silver nitrate $\left(\mathrm{AgNO}_{3}\right)$ as a metallic precursor. Such an approach could guarantee suspended AgNPs through the solution without any additives and toxic substances. Transmission electron microscopy (TEM) micrographs confirmed the formation of an $\mathrm{Ag}^{0}$ nanocluster in the $\mathrm{H}_{4} \mathrm{~L}$ and 1,3,6,8-tetrakis ( $p$-benzoic acid)-pyrene (TBAPy) ligands. The prepared $\mathrm{H}_{4} \mathrm{~L}-\mathrm{AgNPs}$ and TBAPy-AgNPs exhibited remarkable performance as insecticidal agents against BPH. Furthermore, the effect of treatment on enzyme levels in the insect system was explored and the action mechanism addressed as well. To the best of our knowledge, this is the first report on the synthesis, characterization, and insecticidal potential of AgNPs against BPH using the two organic ligands $\mathrm{H}_{4} \mathrm{~L}$ and TBAPy.

\section{Materials and methods Chemicals}

$\mathrm{AgNO}_{3}$, ethanol, tertbutanol, nitrobenzene, 4-methoxycaronylphenyl boronic acid, and tetrakis (triphenylphosphine) palladium were purchased from Sigma-Aldrich (St. Louis, MO, USA). 3,5-Dimethylboronic acid, $\mathrm{KMnO}_{4}$, sodium hydroxide, $\mathrm{H}_{2} \mathrm{SO}_{4}$, 2,5-dibromoaniline, dimethylformamide (DMF), hydrochloric acid, sodium carbonate, palladium acetate, pyrene, nitrobenzene, bromine solution, nitrobenzene, ethyl acetate, $\mathrm{n}$-hexane, potassium tribasic phosphate anhydrous, 1,4-dioxane, chloroform (THE), magnesium sulfate anhydrous, dimethyl sulfoxide, and potassium hydroxide $(\mathrm{KOH})$ were purchased from Aladdin Biochemical Technology Co., Ltd. (Shanghai, China). Proton nuclear magnetic resonance $\left({ }^{1} \mathrm{H}\right.$ NMR) spectra were recorded using a Varian EM-390 spectrometer (USA) $(400 \mathrm{MHz})$ with trimethylsilyl chloride (TMS) as an internal reference, and the chemical shift $(\delta)$ was expressed in parts per million (ppm). Mass spectra were recorded on a Kratos MS (75 eV) instrument (Kyoto, Japan). All reactions were monitored by thin-layer chromatography conducted on $0.2 \mathrm{~mm}$ silica gel 60F-254 (Merck) plates using UV light (245 and $365 \mathrm{~nm}$ ) for detection. Acetylcholine iodide, 5,5-dithiobis-2-nitro benzoic acid, fast blue salt, $\alpha$ - and $\beta$-naphthyl acetate, Folin-Ciocalteu reagent were obtained from Sigma-Aldrich; $\beta$-nitrophenyl phosphate from Biotech (Shanghai, China); and all other chemicals and reagents, of the highest analytical grade, from local companies.

\section{Synthesis of AgNPs with $\mathrm{H}_{4} \mathrm{~L}$ and TBAPy}

AgNPs were prepared by direct reduction of the $\mathrm{Ag}$ source (i.e., $\mathrm{AgNO}_{3}$ ) in the presence of $\mathrm{H}_{4} \mathrm{~L}$ and TBAPy. 
$\mathrm{AgNO}_{3}$ solution $(1,3$, and $5 \mathrm{mM}$ ) was prepared in $150 \mathrm{~mL}$ of Milli-Q water and kept at $60^{\circ} \mathrm{C}$ in a water bath for $10 \mathrm{~min}$. Then, a defined amount of $\mathrm{H}_{4} \mathrm{~L}$ or TBAPy dissolved in $2 \mathrm{~mL}$ of dimethyl sulfoxide was mixed in with vigorous magnetic stirring at $70^{\circ} \mathrm{C}$ for $2 \mathrm{~h}$ before cooling down to room temperature. The reaction between ligands and $\mathrm{Ag}$ persisted under stirring in the dark at room temperature, and the formation of $\mathrm{Ag}^{0}$ colloidal suspension was observed by optical color change (a reddish-brown color with $\mathrm{H}_{4} \mathrm{~L}$ and a yellowish-black color with TBAPy). Additionally, the reduction of Ag ions to AgNPs was confirmed by sampling an aliquot of the reaction solution $(4 \mathrm{~mL})$ and analyzing it with a UV-Vis spectrophotometer. The $\mathrm{H}_{4} \mathrm{~L}-$ and TBAPy-AgNPs were centrifuged at $10,000 \mathrm{rpm}$, and the colloidal suspension was collected and maintained in a vacuum oven at $120^{\circ} \mathrm{C}$ for $2 \mathrm{~h}$ before further characterization.

\section{Characterization of synthesized AgNPs UV-Vis spectral analysis of AgNPs}

The UV-Vis patterns of the AgNP samples were recorded using $1 \mathrm{~mL}$ of AgNPs diluted with $3 \mathrm{~mL}$ of double-distilled water on a UV-2550 spectrophotometer (Shimadzu, Japan) at a wavelength of $200-800 \mathrm{~nm}$ with a resolution of $1 \mathrm{~nm}$ [29].

\section{FT-IR analysis of AgNPs}

Spectra of the dry powder of the AgNP samples were recorded under identical conditions at $500-4000 \mathrm{~cm}^{-1}$ with an amplitude of $4 \mathrm{~cm}^{-1}$ using Fourier transform infrared spectrometer (FT-IR, Vector 22; Bruker Corporation, Germany). Before measurements, $1 \mathrm{mg}$ of the AgNP sample was mixed with $300 \mathrm{mg}$ of $\mathrm{KBr}$, cast into circular pellets, and stabilized under reactive humidity.

\section{EDX analysis of AgNPs}

The surface of the as-synthesized AgNP samples was viewed by an energy-dispersive X-ray spectroscopy (EDX, SU-8010; Hitachi, Japan). A thin film of the prepared AgNP samples was deposited onto a well-cleaned silicon substrate and gently dried. Next, the samples were attached to a circular metallic stud by carbon tape and inserted into the vacuum chamber of the microscope using a cylindrical lever. Analyses were performed at an accelerating voltage of $3 \mathrm{kV}$.

\section{TEM and XRD analyses of AgNPs}

The morphologies and microstructures of the obtained $\mathrm{H}_{4} \mathrm{~L}-$ and TBAPy-AgNPs were observed by TEM (JEOLJEM-1230; JEOL, Japan) operated at an accelerating voltage of $200 \mathrm{kV}$. The samples were mixed with ethanol under gentle sonication to disperse the powder into the solution well. A drop of the suspension was pipetted onto a copper grid and then dried at room temperature. The phase purity and crystalline structure of the as-synthesized compounds were measured by wide-angle X-ray diffraction (XRD) using a Siemens X-ray diffractometer (Siemens, Germany). The XRD patterns were collected with a monochromated $\mathrm{CuK \alpha}$ radiation source at a potential of $40 \mathrm{kV}$ and a current of $30 \mathrm{~mA}$ [30].

\section{Dynamic light scattering (DLS) and Zeta potential}

The average particle size and size distribution of AgNPs were evaluated using the particle size analyzer system (Zeta sizer, Malvern Instruments Ltd., USA), with the same device, the zeta potential of AgNPs was measured to determine the stability of nanoparticles.

\section{Insect rearing}

$\mathrm{BPH}$ adults were initially gathered from rice fields in Hangzhou, Zhejiang Province, China, and reared on a susceptible variety of rice (TN1) in net cages at $26 \pm 2{ }^{\circ} \mathrm{C}$ in a $14: 10$ h light:day (L:D) cycle at $70 \%-80 \%$ relative humidity in the Laboratory of Urban Entomology, Institute of Insect Sciences, Zhejiang University, China. All tested insects were preserved on the same rice variety. Both sexes of BPH were collected from the population (20 individuals/replicate) and used in the experiment.

\section{Toxicity tests of two AgNP-ligand complexes against the brown planthopper}

The standard methods to determine the lethal concentration of $\mathrm{H}_{4} \mathrm{~L}-$ and TBAPy-AgNPs on $\mathrm{BPH}$ adults were followed. Before defining the final doses of compounds, a preliminary test was performed to determine the dosage range of an insecticide with different levels of mortality before conducting toxicity tests. The concentrations of all samples were $500,1000,1500$, and $2000 \mathrm{mg} / \mathrm{L}$ prepared in a $100 \mathrm{~mL}$ beaker Borosil (Mumbai, India) using deionized water as a solvent for the two ligands without $\mathrm{Ag}$ (positive control). For toxicity tests, $\mathrm{H}_{4} \mathrm{~L}-$ and TBAPyAgNP colloids were diluted using double-distilled water as a solvent to the desired concentrations $(5,10,15$, and $20 \mathrm{mg} / \mathrm{L}$ ). Dimethyl sulfoxide was used as a negative control. Next, $20 \mathrm{BPH}$ adults per replicate were released on rice plants in plastic cups $(500 \mathrm{~mL})$ and covered with water-impregnated cotton. After spraying the prepared compounds, all cups were covered with muslin cloth held in place with rubber bands to prevent the insects from escaping during the experiment. Each toxicity test, including a set of the control group (distilled water), was 
tested with four replicates of four concentrations of each compound. The plastic cups with treated insects were put into an incubator at $26 \pm 1{ }^{\circ} \mathrm{C}$ in a $14: 10 \mathrm{~h} \mathrm{~L}: \mathrm{D}$ photoperiod. Mortality was recorded at $24 \mathrm{~h}$ intervals up to 10 days after spraying. Moribund insects were also considered for determining mortality after gentle prodding with a fine brush.

\section{Mechanisms of action of AgNPs on N. lugens Preparation of whole-body homogenates}

The treatment and control BPH groups (15 adult individuals per group) were pooled and homogenized in Eppendorf tubes (held in crushed ice) using a Teflon hand homogenizer in $1 \mathrm{~mL}$ of $0.9 \%$ saline for ultimate estimation of total proteins, acetylcholine, esterases, and phosphatases action. The whole-body $\mathrm{BPH}$ homogenates were centrifuged at $12,000 \times g$ and $4{ }^{\circ} \mathrm{C}$ for $10 \mathrm{~min}$, and the clear supernatants were used for biochemical examination. The solution for homogenization and glassware were kept at $4{ }^{\circ} \mathrm{C}$ before use, and the homogenates were hung on ice before further investigation.

\section{Determination of protein concentration}

The proteins in $\mathrm{BPH}$ whole-body homogenates were first precipitated by $80 \%$ ethanol [31], and the protein concentration was estimated using the Lowry method [32].

\section{Acetylcholinesterase assays}

With slight modifications, acetylcholinesterase activity in the BPH whole-body homogenates was spectrophotometrically measured using acetylcholine iodide as a substrate [33]. Each aliquot of the homogenate $(200 \mu \mathrm{L})$ was mixed successively with $200 \mu \mathrm{L}$ of sodium phosphate

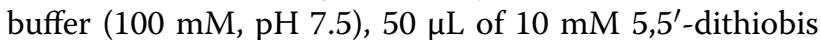
(2-nitrobenzoic acid) (DTNB) and $50 \mu \mathrm{L}$ of $12.5 \mathrm{mM}$ acetylcholine iodide. After incubation for $5 \mathrm{~min}$ at room temperature, the optical density of the samples was tested at $400 \mathrm{~nm}$ against a suitable reagent blank.

\section{Esterase assay}

Carboxylesterase activity in the whole-body $\mathrm{BPH}$ homogenates was determined using the Van Asperen method [34]. Briefly, $200 \mu \mathrm{L}$ of control and treatment BPH homogenates was mixed with $2 \mathrm{~mL}$ of the $\alpha$ - or $\beta$-naphthyl acetate solution, and the reaction was extended for $30 \mathrm{~min}$ at room temperature. After incubation, $500 \mu \mathrm{L}$ of fast blue sodium dodecyl sulfate (SDS) reagent was added $(22.5 \mathrm{mg}$ OF fast blue salt in $2.25 \mathrm{~mL}$ OF distilled water and $5 \% \mathrm{w} / \mathrm{v}$ SDS in $0.2 \mathrm{M}$ phosphate buffer; $\mathrm{pH}$ 7.2), and the color was allowed to develop for $15 \mathrm{~min}$ at room temperature. The optical density of the samples was measured at $588 \mathrm{~nm}$ using a spectrophotometer against the respective reagent blank.

\section{Phosphatase assay}

The levels of acid and alkaline phosphatases in the whole-body $\mathrm{BPH}$ homogenates were measured using the Asakura method with slight modifications [35]. Acid phosphatase activity was estimated by mixing $100 \mu \mathrm{L}$ of insect homogenate with $400 \mu \mathrm{L}$ of $50 \mathrm{mM}$ sodium acetate buffer (pH 4.0) and $500 \mu \mathrm{L}$ of $15 \mathrm{mM} \beta$-nitrophenyl phosphate. Alkaline phosphatase activity was estimated by mixing $100 \mu \mathrm{L}$ of BPH homogenate with $400 \mu \mathrm{L}$ of $50 \mathrm{mM}$ Tris- $\mathrm{HCl}$ buffer (pH 8.0) and $500 \mu \mathrm{L}$ of $15 \mathrm{mM}$ p-nitrophenyl phosphate. After incubation for $15 \mathrm{~min}$ at $37^{\circ} \mathrm{C}$ in a water bath, the enzymatic reaction was stopped by adding $100 \mu \mathrm{L}$ of $0.5 \mathrm{~N} \mathrm{NaOH}$ solution and centrifuged at $4000 \times g$ for $5 \mathrm{~min}$. Absorbance of the resulting clear supernatant from each sample was checked at $440 \mathrm{~nm}$ against the appropriate reagent blank.

\section{Determination of AgNP content in the brown planthopper by TEM}

The AgNP accumulation in the adult BPH body was evaluated by TEM [36]. Briefly, midgut extracts of AgNP treatment $\left(\mathrm{LC}_{30}\right)$ and control groups were collected, anesthetized, and fixed in $2.5 \%$ glutaraldehyde in $0.1 \mathrm{M}$ phosphate buffer ( $\mathrm{pH} 7.2)$ for $48 \mathrm{~h}$ at $4{ }^{\circ} \mathrm{C}$. The samples were washed several times with phosphate-buffered saline (PBS) for 15-20 min each time, then postfixed in $2 \%$ aqueous osmium tetroxide for $1-2 \mathrm{~h}$, washed again with distilled water four to six times for 30-45 min each time, dehydrated in a series of alcohols, and embedded in spur resin. The samples were incubated at $80^{\circ} \mathrm{C}$ overnight for complete polymerization. Ultrathin Sects. $(50-70 \mathrm{~nm})$ were cut with a glass knife on an ultramicrotome (LEICA EM UC7 ultratome) and then mounted on copper grids. The sections were stained with uranyl acetate and alkaline lead citrate for 5-10 min, and the samples were characterized with TEM (Model H-7650 TEM; Hitachi-Japan).

\section{Histological analysis}

Histological analysis of the BPH digestive system was performed using adult insects (treatment and control groups). Briefly, $20 \mathrm{BPH}$ adults were exposed to a median lethal concentration $\left(\mathrm{LC}_{50}\right.$ ) of $\mathrm{H}_{4} \mathrm{~L}$, TBAPy, $\mathrm{H}_{4} \mathrm{~L}-\mathrm{AgNPs}$, and TBAPy-AgNPs for 5 days, as previously described [37] with a small modification. Briefly, the insects were fixed in 10\% buffered formaldehyde for $48 \mathrm{~h}$, dehydrated using a graded series of ethanol, and cleared with xylene solution. Next, they were embedded in paraffin blocks using melted paraffin at the embedding station. The paraffin blocks were cut into $5-\mu \mathrm{m}$-thick sections using a rotary microtome and stained with hematoxylin and eosin. The glass slides were examined for abnormalities under a light microscope. 


\section{Data analysis}

The mortality (\%) of BPH treated with $\mathrm{H}_{4} \mathrm{~L}-$ and TBAPyAgNPs were subjected to probit analysis for calculating $\mathrm{LC}_{50}$ and $\mathrm{LC}_{90}$ with $95 \%$ confidence limits of lower and upper values [38]. For evaluating the biological variables observed in the experiments, one-way analysis of variance (ANOVA) and Duncan's test were performed to assess the variation between both treatments. Chi-square values and all analyses were analyzed using CoStat ver. 6.311 (CoHort Software, Monterey, USA), and SPSS Statistics ver. 16.0 (SPSS Inc., Chicago, IL, USA).

\section{Results and discussion}

\section{Synthesis of $\mathrm{H}_{\mathbf{4}} \mathrm{L}$ and TBAPy}

$\mathrm{H}_{4} \mathrm{~L}$ and TBAPy are two organic ligands formed during the synthesis of the frameworks $\mathrm{L}_{(\mathrm{Cu})}$ and NU-1000 [39, 40]. However, this study is the first attempt to prepare a Ag colloidal suspension as an insecticide using these ligands. $\mathrm{H}_{4} \mathrm{~L}$ was obtained from the chemical reaction of 3,5-dimethylphenylboronic acid to form benzene-3,5-dicarboxyelester-boronic acid [41], and the final product was obtained according as previously described with slight modifications [40]. The reaction by-products and compounds were checked by elemental analysis, such as ${ }^{1} \mathrm{H}$ NMR (Additional file 1: Scheme S1). TBAPy was fabricated via the initial bromination of pyrene, followed by the reaction of tetrabromopyrene with 4-methoxycaronylphenyl boronic acid as previously described with some modifications (Additional file 1: Scheme S2; Figures $\mathrm{S} 1, \mathrm{~S} 2$, and $\mathrm{S} 3$ ).

\section{Formation mechanism of $\mathrm{H}_{4} \mathrm{~L}$ - and TBAPy-AgNPs}

$\mathrm{H}_{4} \mathrm{~L}-$ and TBAPy-AgNPs were constructed by the direct recombination of Ag cations and ligand anions throughout the electrostatic attraction. The anchoring of $\mathrm{Ag}^{+}$ into the organic ligands to form $\mathrm{H}_{4} \mathrm{~L}-$ and TBAPyAgNPs via a simple liquid-phase reduction process was confirmed by different analyses, such as FT-IR, UV-Vis spectroscopy, XRD, TEM, and EDX, as described later. We proposed that the functional groups induced onto the surfaces of ligands facilitate the nucleation of Ag seeds at the start of the reaction and the primarily grown seeds tend to aggregate and recrystallize to form quasi-spherical AgNPs after a prolonged period of growth (Fig. 1). Furthermore, the induced functional groups might improve the binding between the metallic cations and the ligand species in the resulting complexes.

\section{Characterization of $\mathrm{H}_{4} \mathrm{~L}-$ and TBAPy-AgNPs UV-Vis spectroscopy}

UV-Vis spectroscopy is a technique for verifying NP development in a solution. In this study, the integrated $\mathrm{H}_{4} \mathrm{~L}-$ and $\mathrm{TBAPy}-\mathrm{AgNO}_{3}$ systems underwent a chemical reduction process, and the change in color to a reddish-brown for $\mathrm{H}_{4} \mathrm{~L}$ or yellowish-black for TBAPy indicated the formation of a $\mathrm{Ag}$ colloidal suspension (Fig. 2A, B). The obtained complexes were primarily observed by a UV spectrophotometer, and the recorded signals displayed major absorption peaks centered at 425 and $430 \mathrm{~nm}$ for $\mathrm{H}_{4} \mathrm{~L}-$ and TBAPy-AgNPs, respectively, which is mainly indexed to generate AgNPs (Fig. 2C). Such characteristics match well with those observed for a single SPR at 405, 420, 448, and $450 \mathrm{~nm}[10,11,42]$. The deviation of the SPR shoulder of anisotropic particles might be attributable to their shape and size [43, 44]. However, the control samples prepared without $\mathrm{AgNO}_{3}$ salt depicted an SPR peak at $230 \mathrm{~nm}$ originated from the organic matrices (Fig. 2C).

\section{FT-IR analysis}

FT-IR measurements were performed to obtain detailed information about the formation mechanism of AgNPs and functional groups. The responses of the as-designated $\mathrm{H}_{4} \mathrm{~L}-$ and TBAPy-AgNPs were collected in the range from 500 to $4000 \mathrm{~cm}^{-1}$ (Fig. 3). The absorption bands of $\mathrm{H}_{4} \mathrm{~L}-\mathrm{AgNPs}$ were detected at 3384, 1698, 1380,1013 , and $522 \mathrm{~cm}^{-1}$ owing to the vibration of the chemical particles of $\mathrm{H}_{4} \mathrm{~L}$. For TBAPy-AgNPs, the characteristic bands were located at 3397, 1687, 1413, 1017, and $521 \mathrm{~cm}^{-1}$ within the same wavenumber window. The broad absorption peaks at 3384 and $3397 \mathrm{~cm}^{-1}$ for $\mathrm{H}_{4} \mathrm{~L}-$ and TBAPy-AgNPs, respectively, can be attributed to the strong vibration modes of $\mathrm{O}-\mathrm{H}$ stretching and bending, while the sharp characteristics peaks at 1698 and $1687 \mathrm{~cm}^{-1}$ for $\mathrm{H}_{4} \mathrm{~L}-$ and TBAPy-AgNPs, respectively, are associated with the stretching vibration of carboxylic acid and some variable stretching and bending peaks that would be involved in the growth process of AgNPs [41]. In addition, the peak shift from 1380 to $1013 \mathrm{~cm}^{-1}$ for $\mathrm{H}_{4} \mathrm{~L}-\mathrm{AgNPs}$ and from 1413 to $1017 \mathrm{~cm}^{-1}$ for TBAPy-AgNPs is largely ascribed to the contribution of the $-\mathrm{C}-\mathrm{H}$ and $\mathrm{O}-\mathrm{H}$ bending vibration of aliphatic and aromatic $\mathrm{C}-\mathrm{H}$ plane distortion vibrations of methyl, methylene, and methoxy groups during reduction. Such characteristic modes demonstrate the extended vibrational bands in charge of compounds such as flavonoids and terpenoids [44-46]. 


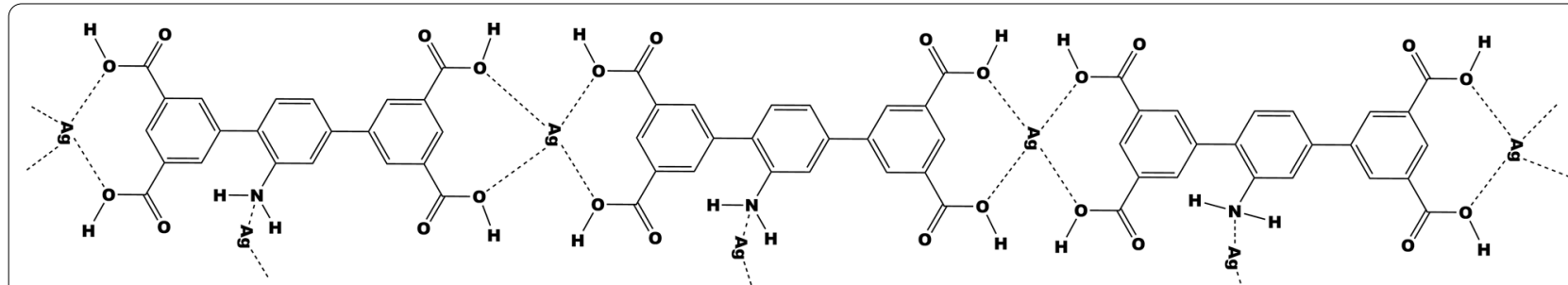

$\mathrm{H}_{4} \mathrm{~L}-\mathrm{Ag}^{0} \mathrm{NPs}$

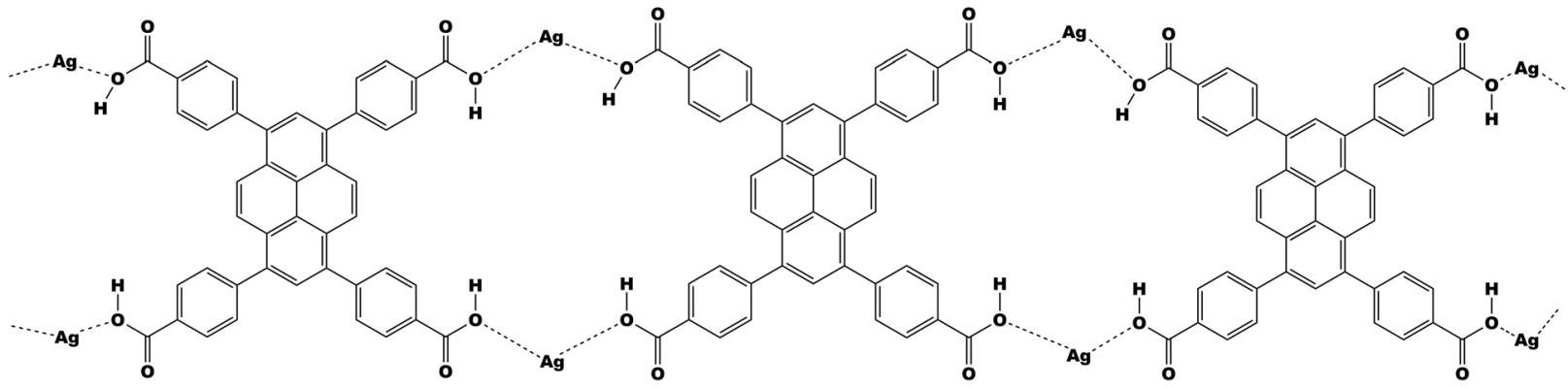

TBAPy-Ag ${ }^{0}$ NPs

Fig. 1 Hydrogen bonds form between organic ligands and silver after the process of reduction of $\mathrm{Ag}^{+}$to $\mathrm{Ag}^{0}$ nanoparticles

\section{TEM, XRD, and EDX analyses of AgNP-based complexes}

The microstructure and surface morphologies of the as-synthesized AgNPs were analyzed by TEM (Fig. 4). The TEM images of both $\mathrm{H}_{4} \mathrm{~L}-$ and TBAPy-AgNPs at different concentrations of $\mathrm{AgNO}_{3}$ showed more microscopic structures of $\mathrm{Ag}^{0}$-intercalated organic ligands. The organic frameworks displayed thin films of biomolecules that are beneficial for attaining highly stable nanocrystals for prolonged durations. The samples exhibited quasi-spherical AgNPs anchored into the entire film of the underlying substrates etched into a porous structure. These AgNPs were firmly interconnected to the transparent networks, which is probably due to the electrostatic interaction between the metallic cations and the surface functional groups of
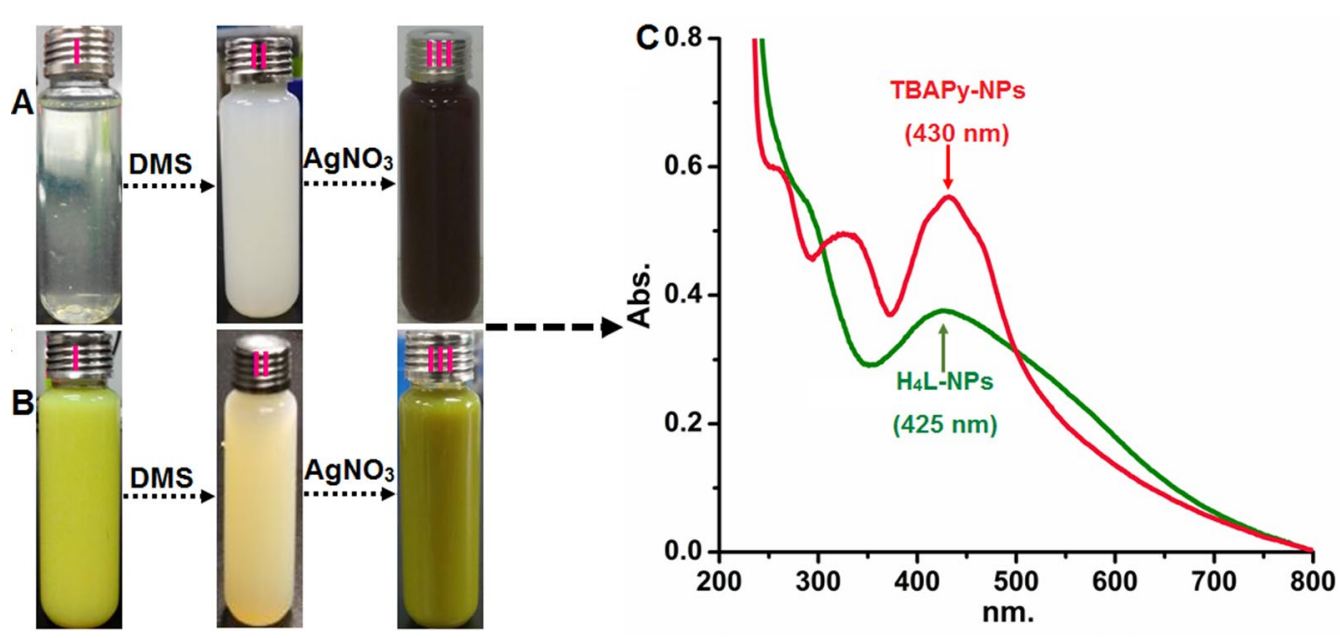

Fig. 2 The preparation process of AgNPs, and variation of color changes in tested compounds. A (I) aqueous solution containing $\mathrm{H}_{4} \mathrm{~L}$ and DMSO, (II) the solution containing $\mathrm{AgNO}_{3}$ (III) after the process of reduction of $\mathrm{Ag}^{+}$to $\mathrm{Ag}^{0}$ with changed color to reddish-brown. $\mathbf{B}$ (I) aqueous solution containing TBAPy and DMSO, (II) the solution containing $\mathrm{AgNO}_{3}$, (III) after the process of reduction of $\mathrm{Ag}^{+}$to $\mathrm{Ag}^{0}$ nanoparticles with changed color to yellowish-black. $\mathrm{C} U V$-Vis absorption spectra of AgNPs synthesized using $\mathrm{H}_{4} \mathrm{~L}$ and TBAPy 
the organic matrices, as well as interfacial interaction among NPs (Fig. 4). The dispersion of the $\mathrm{Ag}^{0}$ nanocluster formed by $\mathrm{H}_{4} \mathrm{~L}$ was better than that TBAPy, suggesting a relatively low growth rate of NPs formed by $\mathrm{H}_{4} \mathrm{~L}$ (Fig. $4 \mathrm{C}$ ). The NPs formed by TBAPy revealed a lumpy morphology made up of agglomerated NPs (Fig. 4D-F). The $\mathrm{Ag}^{0}$ particles produced by both ligands appeared thicker with increasing $\mathrm{AgNO}_{3}$ concentration to 3 and $5 \mathrm{mM}$ because of their high tendency to aggregate into larger clusters (Fig. 4 and Additional file 1: Figure S4), which is a result expected due to ultrafast dissociation of $\mathrm{AgNO}_{3}$ into water and thereby rapid growth kinetics. The darker areas are mainly associated with the agglomeration and condensed overlapping of the adjacent NPs because of thermodynamic kinetic changes. It seems reasonable that the reduction mode and growth mechanism of NPs evolves with the nature of the reducing agent and is strongly correlated with reaction conditions, such as time, temperature, and reactant concentration.

Accordingly, the reduction rate of AgNPs was fast at the initial stage of nucleation and crystallization. The freshly formed nanocrystals are thermodynamically unstable, owing to their high surface energies. Subsequently, these nanoclusters were guided to drive the following stage of self-assembly with extra generated nanocrystals into larger NPs by changing the corresponding interfacial energies. Moreover, the heating of the reaction solution with strong reflux may facilitate AgNP formation. We proposed that the variation in nanocrystal free energies might probably play a role in influencing the reaction kinetics and nucleation mechanism. It is worth mentioning that the architecture and geometry of the constructed NPs could significantly influence biological systems, particularly pest administration programs [47]. Accordingly, the obtained AgNPs are expected to play an important role in contributing to insecticidal assays.

The crystalline structure of the obtained AgNPs was studied by XRD analysis, as illustrated in Fig. 5. The $\mathrm{H}_{4} \mathrm{~L}$-AgNP spectrum (Fig. 5A) exhibited five diffraction peaks at $2 \theta$ of $32.18^{\circ}, 37.91^{\circ}, 46.16^{\circ}, 57.60^{\circ}$, and $77.29^{\circ}$, indexed to [101], [111], [200], [220], and [311] planes of standard face-centered cubic AgNPs, respectively. The TBAPy-AgNP spectrum (Fig. 5B) displayed five major peaks at $2 \theta$ of $32.18^{\circ}, 38.04^{\circ}, 46.29^{\circ}, 54.80^{\circ}$, and $76.76^{\circ}$, reflecting the [101], [111], [200], [220], and [311] diffractions of the cubic Ag phase, respectively. The slight change in the diffraction positions is probably due to the change in the chemical microstructure of the ligands. We believe that the induced strain can affect the character of nanocrystallites in the crystal structure. These results are consistent with those obtained for AgNPs prepared by

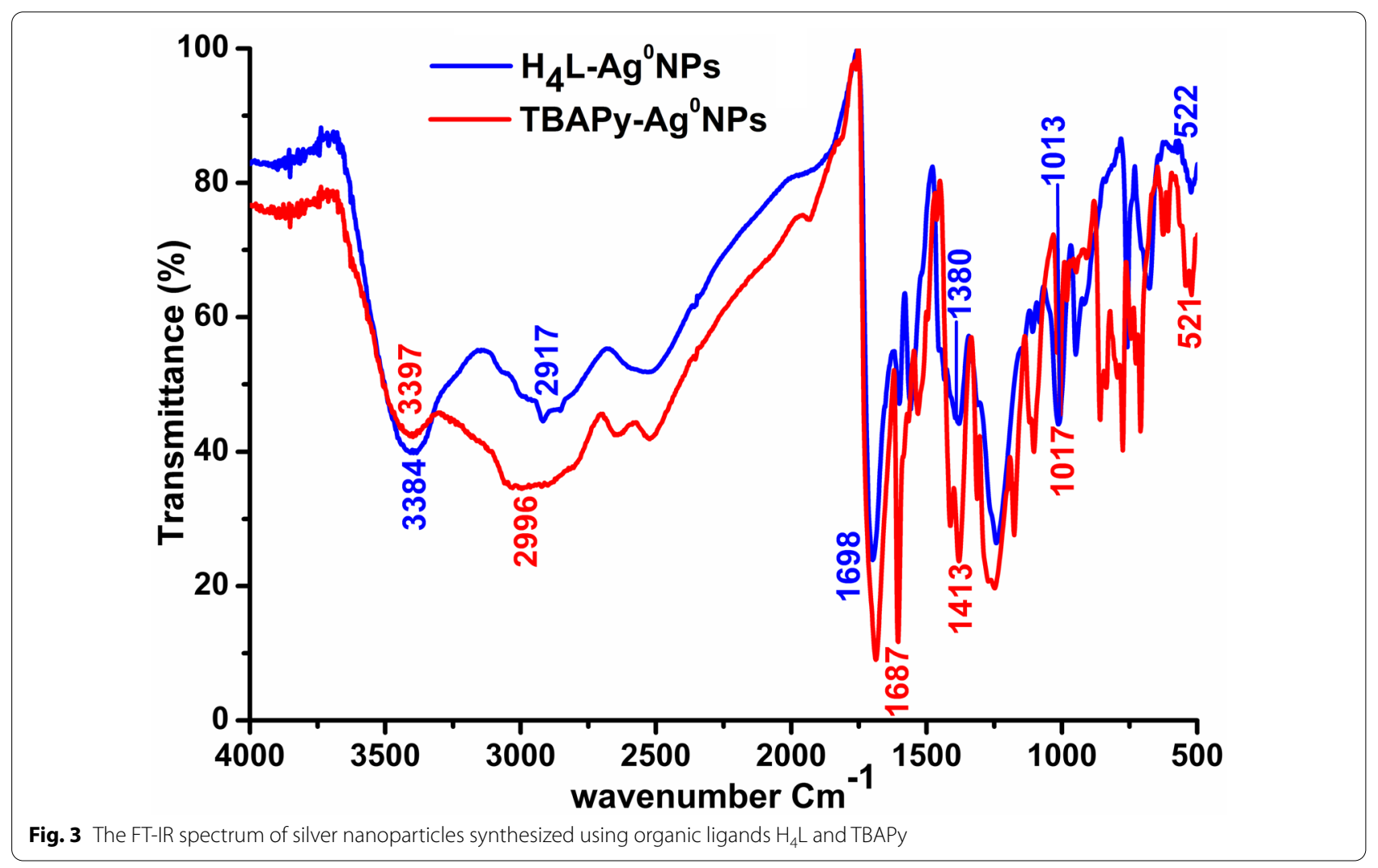




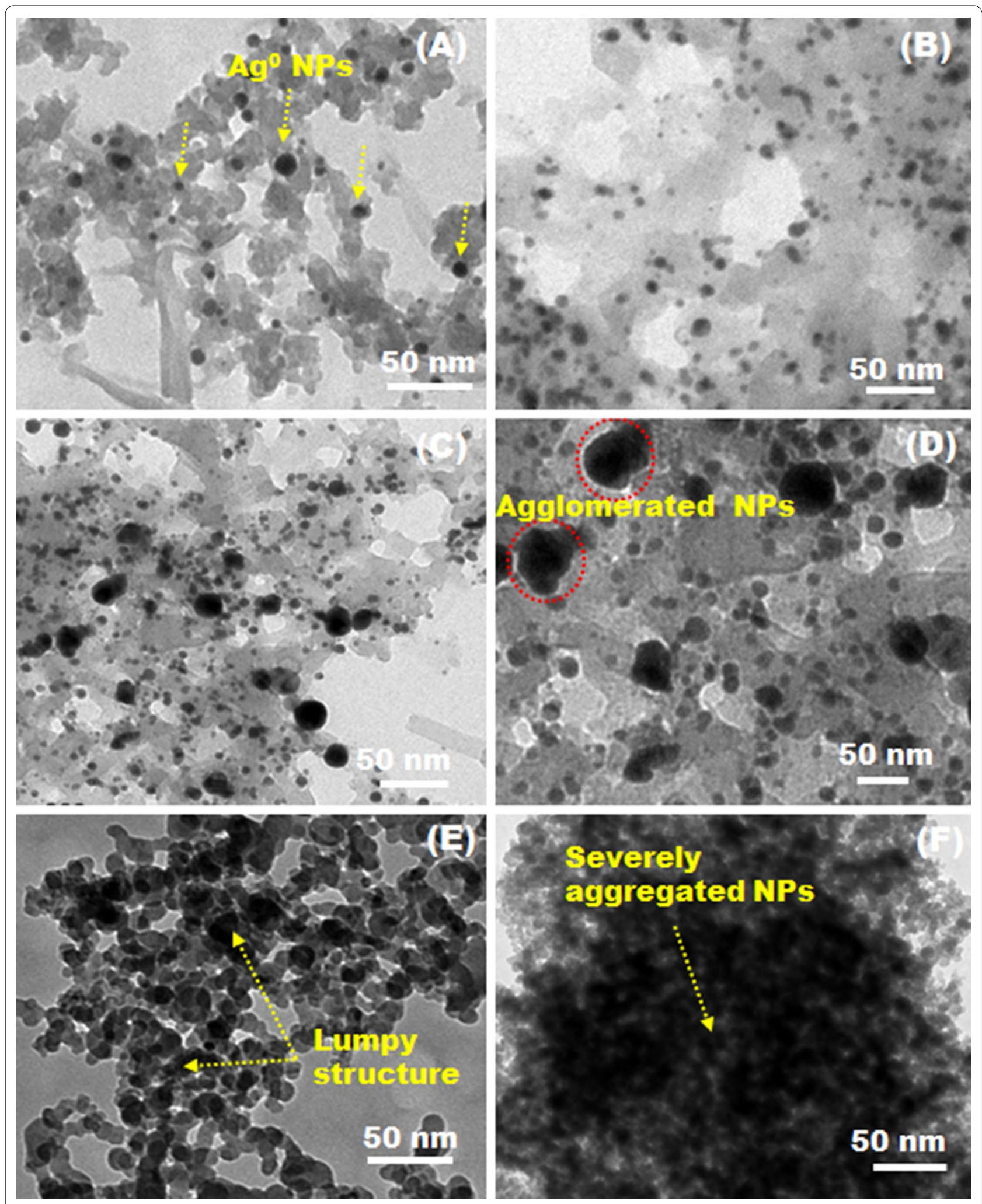

Fig. 4 TEM micrographs of the as-prepared complexes. A-C $\mathrm{H}_{4} \mathrm{~L}-$-AgNPs and $\mathbf{D}-\mathbf{F}$ TBAPy-AgNPs. The observation illustrates the growth of particles for both complexes at different $\mathrm{AgNO}_{3}$ concentrations; $\mathbf{A}$ and $\mathbf{D} 1 \mathrm{mmol}, \mathbf{B}$ and $\mathbf{E} 3 \mathrm{mmol}$, and $\mathbf{C}$ and $\mathbf{F} 5 \mathrm{mmol}$ 
using the cell-free supernatants of two bacteria Bacillus amyloliquefaciens and B. subtilis [11].

The composition and elemental analysis of both $\mathrm{H}_{4} \mathrm{~L}-$ and TBAPy-AgNPs are illustrated Additional file 1: Figure S5. The mapping profiles of both complexes demonstrated that the bulk Ag represents the major component. The spectra of both $\mathrm{H}_{4} \mathrm{~L}-$ and TBAPy-AgNPs (Additional file 1: Figures S6A and S6B) displayed a strong peak at $3 \mathrm{keV}$ attributed to AgNPs and demonstrated the reduction of $\mathrm{Ag}^{+}$to $\mathrm{Ag}^{0}$ with the assistance of $\mathrm{H}_{4} \mathrm{~L}$ and TBAPy capping salts. Besides, $\mathrm{Al}, \mathrm{S}, \mathrm{Si}, \mathrm{Cl}$, and $\mathrm{O}$ probably originated from the silicon substrate used to prepare the samples prior to EDX analysis and the organic precursors used to prepare the two ligands. The corresponding cross-sectional compositional line profiles displaced that the Ag intensity is much stronger than that of other elements detected, which evidences the predominance of Ag in the NPs. These findings agree well with the reported EDX profiles and existing results in the literature $[43,48]$ and indicate the effectiveness of our ligands as environmentally friendly compounds to create $\mathrm{Ag}^{0}$-based complexes. Additionally, this may be an efficient strategy to prepare other noble metal NPs.

\section{Nanoparticle size and stability of the nanoparticles}

The average size of $\mathrm{H}_{4} \mathrm{~L}-\mathrm{AgNP}$ was found to be $7 \mathrm{~nm}$ to $75 \mathrm{~nm}$, while the particle size of TBAPy-AgNP was found to be $10 \mathrm{~nm}$ to $85 \mathrm{~nm}$ (Additional file 1: Figure S7A, B). The zeta potential is usually utilized to know the constancy of colloidal systems. The zeta potential of nanoparticles was evaluated in methanol as dispersant. In this report, zeta potentials of $\mathrm{H}_{4} \mathrm{~L}-$ and TBAPy-AgNPs were $-28.1 \mathrm{mV}$ and $-27.2 \mathrm{mV}$, which denoted the stability of silver nanoparticles suspensions (Additional file 1: Figure S7C, D). Mostly, a suspension that displays an absolute zeta potential less than $20 \mathrm{mV}$ is considered unstable and will cause precipitation of particles from solution, while the absolute zeta potential higher than $20 \mathrm{mV}$ is stable $[49,50]$. Guilger-Casagrande et al. reported that all the samples of nanoparticles presented negative values with the AgNP-TS sample showing the highest electronegativity $-33.3 \mathrm{mV}$ [51].

\section{Toxicity of AgNPs toward unsexed brown planthopper adults}

Immediate toxicity bioassay demonstrated that $\mathrm{H}_{4} \mathrm{~L}-$ and TBAPy-AgNPs are toxic to unsexed adult BPH. The concentration of our applied materials and the posttreatment time significantly affected the mortality for all tested adult insects. At high concentrations (1500 and $2000 \mathrm{mg} / \mathrm{L})$, the toxicity of $\mathrm{H}_{4} \mathrm{~L}(71.25 \%$ and $78.50 \%$, respectively) was higher than that of TBAPy $(64.50 \%$ and $70.50 \%$, respectively) 10 days posttreatment (Additional file 1: Figure S8A). Similarly, at low concentrations (15 and $20 \mathrm{mg} / \mathrm{L}$ ), $\mathrm{H}_{4} \mathrm{~L}-\mathrm{AgNPs}$ caused higher mortality (92\% and 98\%, respectively) compared with TBAPyAgNPs (70\% and $79 \%$ mortality, respectively) in $\mathrm{BPH}$ adults 10 days posttreatment (Additional file 1Figure S8B). Moreover, TBAPy were less effective against BPH at a high concentration, with an $\mathrm{LC}_{50}$ and $\mathrm{LC}_{90}$ of 810 and $1982 \mathrm{mg} / \mathrm{L}$, respectively, $168 \mathrm{~h}$ posttreatment. However, the toxicity of $\mathrm{H}_{4} \mathrm{~L}$ against $\mathrm{BPH}$ increased, with an $\mathrm{LC}_{50}$ and $\mathrm{LC}_{90}$ of 786 and $1919 \mathrm{mg} / \mathrm{L}$, respectively, $168 \mathrm{~h}$ posttreatment (Table 1). Furthermore, at a similar concentration of dimethyl sulfoxide as a solvent for the two ligands (negative control), there was no obvious effect on adult $\mathrm{BPH} 168 \mathrm{~h}$ posttreatment. However, $\mathrm{H}_{4} \mathrm{~L}-\mathrm{AgNPs}$ were highly toxic to $\mathrm{BPH}$, with an $\mathrm{LC}_{50}$ and $\mathrm{LC}_{90}$ of 3.9 and
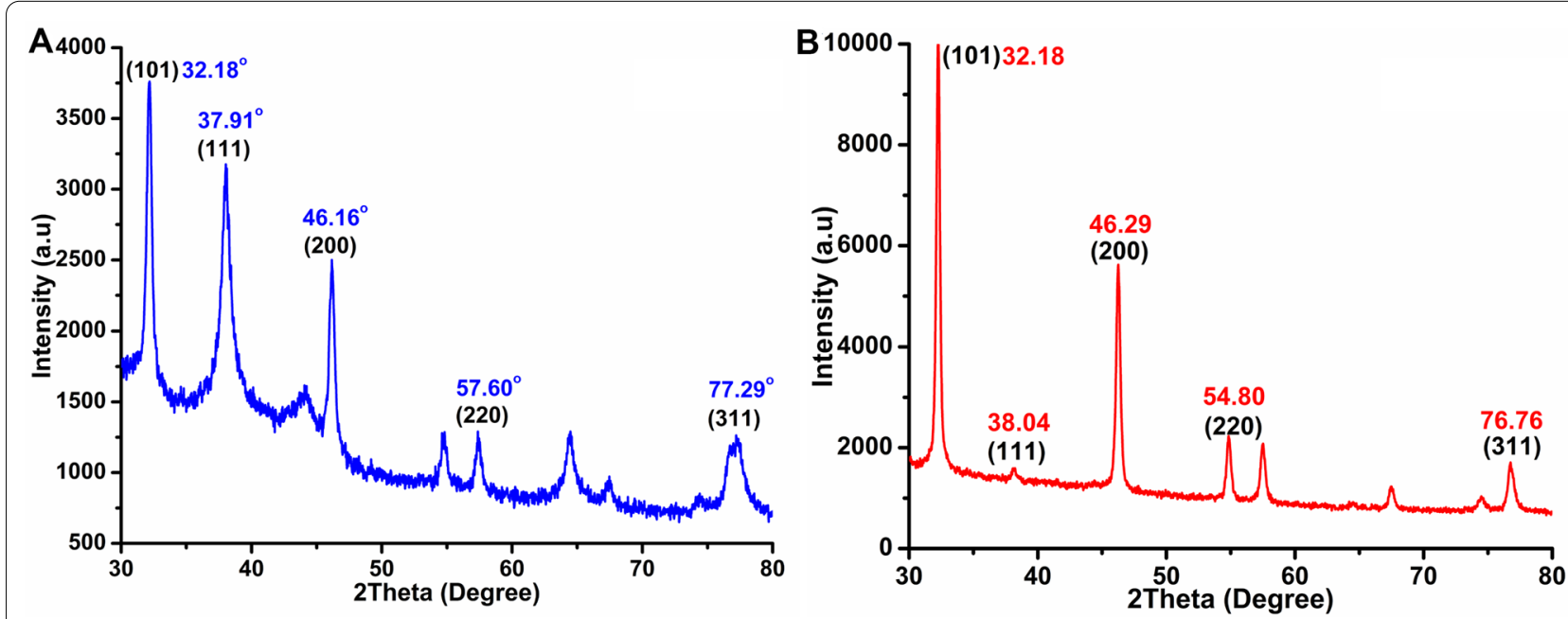

Fig. 5 XRD patterns of synthesized silver nanoparticles $\mathbf{A} \mathrm{H}_{4} L-A g N P$ and $\mathbf{B}$ TBAPy-AgNP 


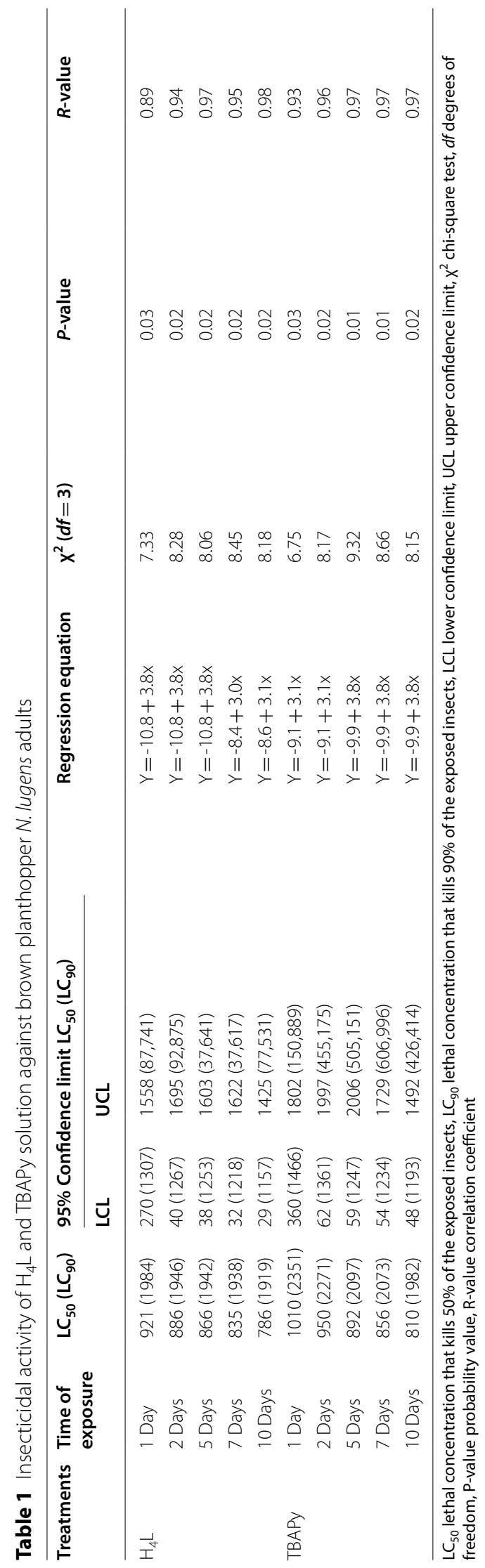


Table 2 Insecticidal effects of synthesized $\mathrm{H}_{4} \mathrm{~L}$-AgNPs and TBAPy-AgNPs against brown planthopper N. lugens adult

\begin{tabular}{|c|c|c|c|c|c|c|c|c|}
\hline \multirow[t]{2}{*}{ Treatments } & \multirow[t]{2}{*}{ Time of exposure } & \multirow[t]{2}{*}{$L C_{50}\left(L C_{90}\right)$} & \multicolumn{2}{|c|}{$\begin{array}{l}\text { 95\% Confidence limit } \\
\mathrm{LC}_{50}\left(\mathrm{LC}_{90}\right)\end{array}$} & \multirow[t]{2}{*}{ Regression equation } & \multirow[t]{2}{*}{$X^{2}(d f=3)$} & \multirow[t]{2}{*}{$P$-value } & \multirow[t]{2}{*}{$R$-value } \\
\hline & & & $\mathrm{LCL}$ & UCL & & & & \\
\hline \multirow[t]{5}{*}{$\mathrm{H}_{4} \mathrm{~L}-\mathrm{NPS}$} & 1 Day & $6.6(18.3)$ & $5.5(15.5)$ & $7.6(23.5)$ & $Y=-2.0+2.5 x$ & 0.13 & 0.94 & 0.99 \\
\hline & 2 Days & $6.2(17.8)$ & $4.9(14.9)$ & $7.2(23.0)$ & $Y=-2.4+3.1 x$ & 0.52 & 0.77 & 0.99 \\
\hline & 5 Days & $5.8(17.8)$ & $4.5(14.9)$ & $6.8(23.7)$ & $Y=-1.6+2.3 x$ & 0.64 & 0.73 & 0.98 \\
\hline & 7 Days & $5.2(17.0)$ & $3.9(14.1)$ & $6.3(22.7)$ & $Y=-1.5+2.5 x$ & 1.34 & 0.51 & 0.97 \\
\hline & 10 Days & $3.9(14.2)$ & $2.5(11.7)$ & $5.1(19.1)$ & $Y=-1.5+2.5 x$ & 2.93 & 0.23 & 0.99 \\
\hline \multirow[t]{5}{*}{ TBAPy-NPs } & 1 Day & $7.1(20.0)$ & $5.8(17.1)$ & $8.1(27.3)$ & $Y=-2.0+2.5 x$ & 0.25 & 0.86 & 0.96 \\
\hline & 2 Days & $6.7(20.0)$ & $5.4(16.6)$ & $7.7(26.7)$ & $Y=-2.0+2.5 x$ & 0.30 & 0.86 & 0.98 \\
\hline & 5 Days & $6.2(19.9)$ & $4.9(16.4)$ & $7.3(27.1)$ & $Y=-2.0+2.5 x$ & 0.24 & 0.89 & 0.97 \\
\hline & 7 Days & $5.9(18.5)$ & $4.6(15.4)$ & $6.9(24.7)$ & $Y=-2.0+2.5 x$ & 0.37 & 0.83 & 0.97 \\
\hline & 10 Days & $4.6(16.1)$ & $3.2(13.3)$ & $5.7(21.9)$ & $Y=-1.5+2.5 x$ & 2.60 & 0.27 & 0.99 \\
\hline
\end{tabular}

$L C_{50}$ lethal concentration that kills $50 \%$ of the exposed insects, $L C_{90}$ lethal concentration that kills $90 \%$ of the exposed insects, $L C L$ lower confidence limit, $U C L$ upper confidence limit, $X^{2}$ chi-square test, $d f$ degrees of freedom, $P$-value probability value, $R$-value correlation coefficient

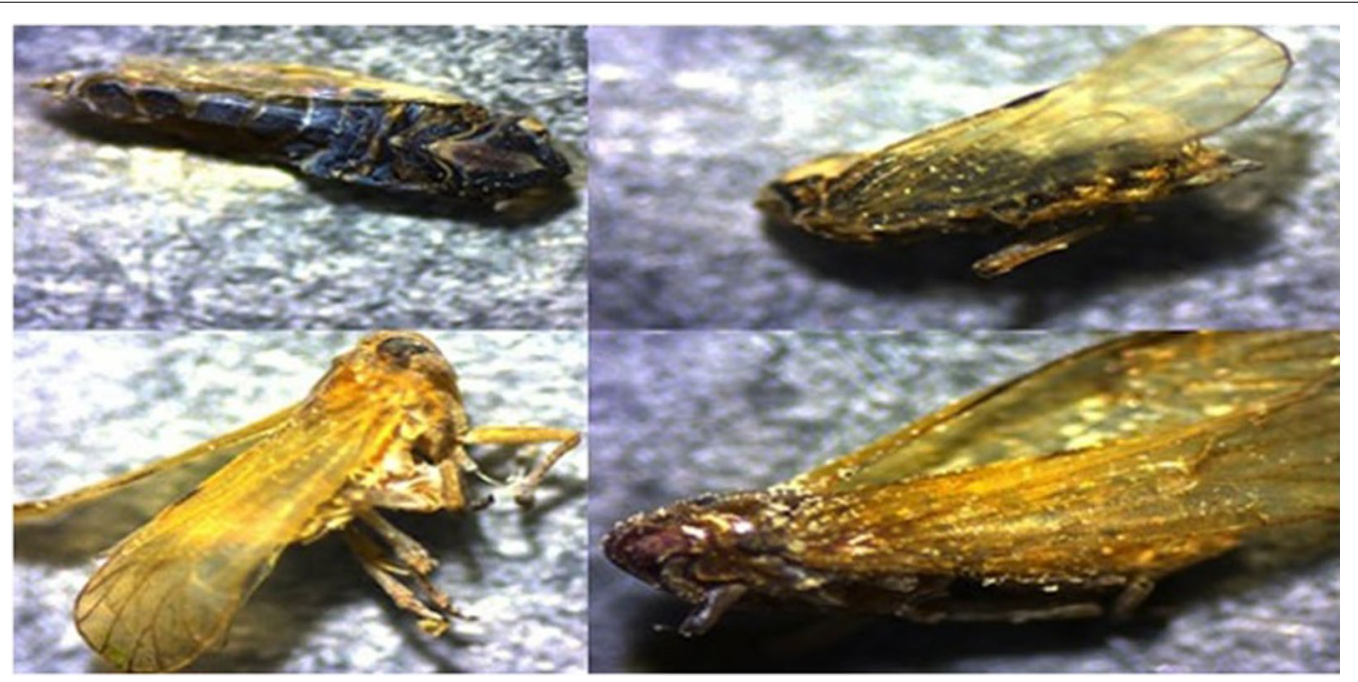

Fig. $6 \mathrm{BPH}$ adults dead after treatment of exposure to $\mathrm{H}_{4} \mathrm{~L}-\mathrm{AgNPs}$ and TBAPy-AgNPs

$14.2 \mathrm{mg} / \mathrm{L}$, respectively, after $168 \mathrm{~h}$ posttreatment, while TBAPy-AgNPs were less toxic at the same concentration, with an $\mathrm{LC}_{50}$ and $\mathrm{LC}_{90}$ of 4.6 and $16.1 \mathrm{mg} / \mathrm{L}$, respectively (Table 2). The regression equation suggested a linear relationship between the rate of mortality and small doses of AgNPs, with a positive relationship between doses, AgNP shapes, and the insect body's absorption of high quantities of AgNPs that caused their death in the end. Over 15 days of careful observation, $100 \%$ mortality was seen in $\mathrm{BPH}$ adult at all concentrations of $\mathrm{H}_{4} \mathrm{~L}-$ and TBAPy-AgNPs (Fig. 6), indicating that insect mortality might largely be due to the toxic inner effects of the AgNPs inside the cuticle. On the basis of our findings, the performance of AgNPs is strongly correlated with the concentration of $\mathrm{AgNO}_{3}$, with the highest activity being achieved with $1 \mathrm{mM}$ for both ligands. In summary, the toxicity and insecticidal activity decreased in the order of $1 \mathrm{mM}>3 \mathrm{mM}>5 \mathrm{mM}$, which might be due to a decrease in reaction exposure.

TEM analysis showed that the agglomeration rate increased with increasing concentration of the Ag precursor (Additional file 1: Figure S4). It is noteworthy that the efficiency of NPs can be negatively affected by such aggregation where specific NPs can participate in the biological reaction, while the remaining become inactive because the reaction takes place on the top layer of the 


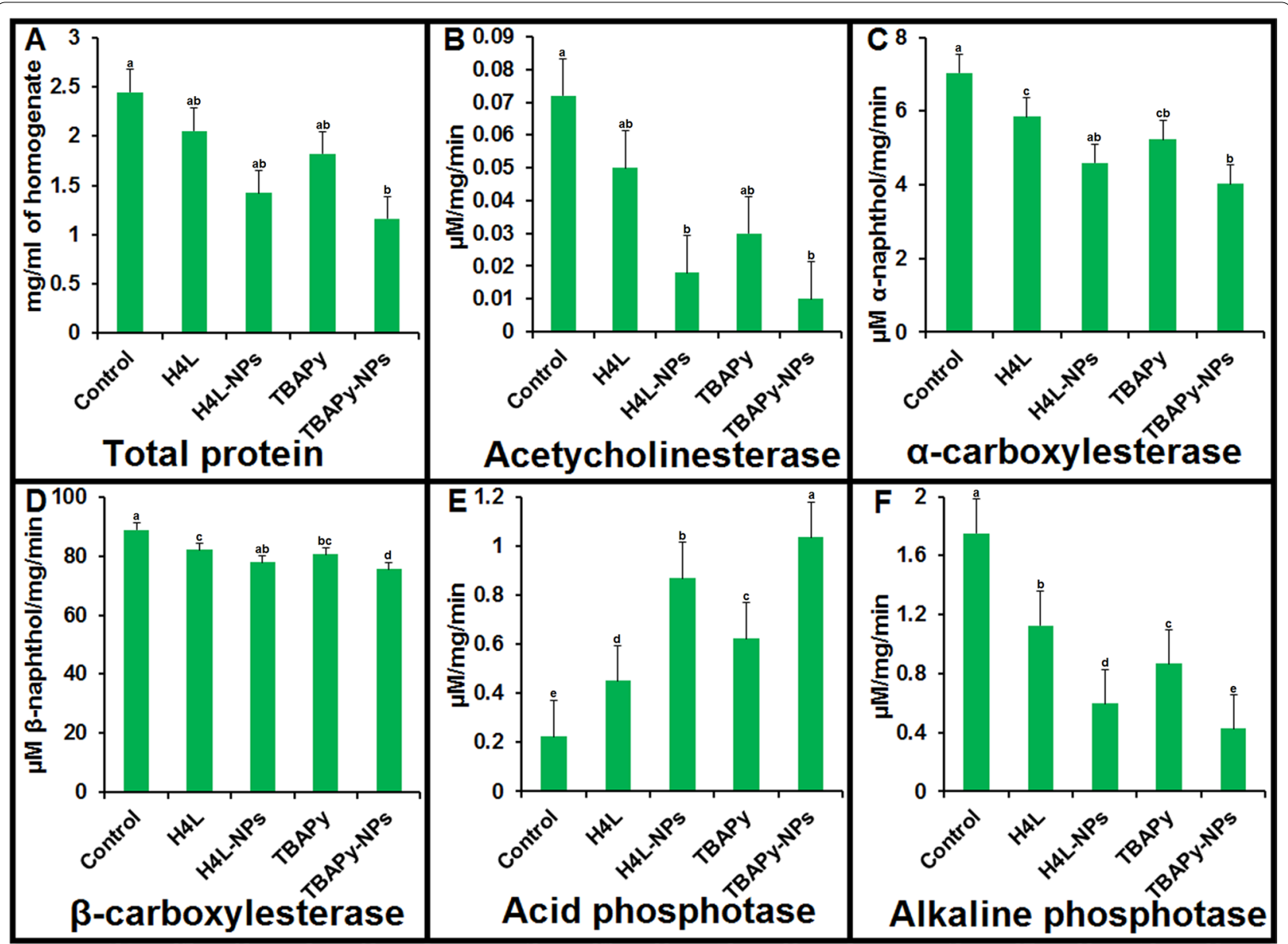

Fig. 7 Effect of $\mathrm{H}_{4} \mathrm{~L}, \mathrm{TBAPy}, \mathrm{H}_{4} \mathrm{~L}-\mathrm{AgNP}$, and TBAPy-AgNP on the enzyme activities and total proteins. A Total protein concentration, $\mathbf{B}$ Acetylcholine esterase, $\mathbf{C}$ a-Carboxylesterase, $\mathbf{D} \beta$-Carboxylesterase, $\mathbf{E}$ acid phosphatase, and $\mathbf{F}$ alkaline phosphatase enzyme. Different letters above the bars of each figure indicate significant differences based on Duncan's test at $p \geq 0.05$ between control and other treatments. Each bar represents the mean $\pm S E$ of four replicates using different preparations of insect homogenates

exposed NPs. In contrast, a well-dispersed nanocluster can guarantee full use of the exposed area to the biological process and all the NPs are efficiently involved (Additional file 1: Figure S4). The cross-activity of NPs driving an individual cell can prevent molting and other physiological procedures that accelerate mortality $[11,52]$. The $\mathrm{LC}_{50}$ was $37.7,31.3$, and $20.7 \mathrm{mg} / \mathrm{L}$ after $24 \mathrm{~h}$ exposure to AgNPs and 25.5, 21.1, and 7.4 $\mathrm{mg} / \mathrm{L}$ after $48 \mathrm{~h}$ exposure to AgNPs against Anopheles stephensi, Culex quinquefasciatus, and Aedes aegypti, respectively [19]. Similarly, the $\mathrm{LC}_{50}$ was $19.7,24.7$, and $26.6 \mu \mathrm{g} / \mathrm{mL}$ and the $\mathrm{LC}_{90}$ was $38.8,53.0$, and $60.3 \mu \mathrm{g} / \mathrm{mL}$ against the early second, third, and fourth instars, respectively, in A. stephensi [50].

Inhibitory activity of $\mathrm{H}_{4} \mathrm{~L}$, TBAPy, and synthesized AgNP-based complexes on brown planthopper enzymes Considering the insecticidal activity of $\mathrm{H}_{4} \mathrm{~L}-$ and TBAPy-AgNPs, it is also necessary to know their mechanism of action. We measured the effects of AgNPs and ligands on the biochemical constituents of BPH. In general, the tested samples caused variation in the normal biochemical constituents of BPH, with either an increase or a decrease in their activity compared to the controls (Fig. 7). We studied on the effects of $\mathrm{H}_{4} \mathrm{~L}-$ AgNPs, TBAPy-AgNPs, and pure $\mathrm{H}_{4} \mathrm{~L}$ and TBAPy on different enzymes involved in biological processes in $\mathrm{BPH}$ adults and estimated total protein levels, acetylcholinesterase activity, $\alpha$ - and $\beta$-carboxylesterase activity, and acid and alkaline phosphatase activity. At $72 \mathrm{~h}$ posttreatment, $\mathrm{H}_{4} \mathrm{~L}-$ and TBAPy-AgNPs significantly decreased the total protein level from the control value of 2.45 to 1.42 and $1.16 \mathrm{mg}$ protein $/ \mathrm{mL}$ of homogenate $(p>0.05)$, respectively (Fig. 7A); significantly decreased acetylcholinestrase activity from the control value of 0.072 to 0.018 and $0.01 \mu \mathrm{M} \mathrm{ACT} / \mathrm{mg} / \mathrm{min}(p>0.05)$, respectively (Fig. 7B); significantly decreased $\alpha$-carboxylesterase 


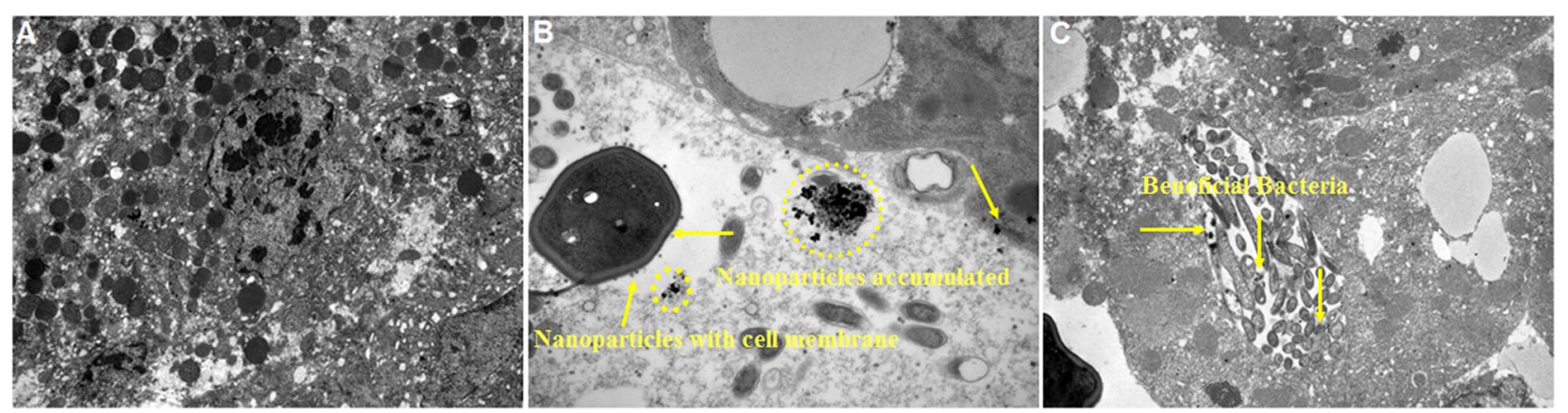

Fig. 8 TEM images of $\mathrm{H}_{4} \mathrm{~L}-\mathrm{AgNP}$, TBAPy-AgNP treated adult, and untreated insect (control). A Ultrastructure of the midgut in control showing midgut microvilli and different cell organelles with normal characteristics. B, C Accumulation of AgNPs in the endoplasmic reticulum, nucleolus, and other cell organelles of gut cells pointed by yellow arrows and circles (dark spots)

activity from the control value of 7.03 to 4.59 and $4.02 \mu \mathrm{M} \quad \alpha$-naphthol/mg/min $(p>0.05)$, respectively (Fig. 7C); and slightly decreased $\beta$-carboxylesterase activity from the control value of 89.02 to 77.86 and $75.55 \mu \mathrm{M}$ $\beta$-naphthol $/ \mathrm{mg} / \mathrm{min} \quad(p>0.05)$, respectively (Fig. 7D). Esterases are the primary enzymes involved in the development of resistance mechanisms to chemical insecticides by splitting carboxyl ester and phosphodiester bonds [53]. We found that $\mathrm{H}_{4} \mathrm{~L}-$ and TBAPy-AgNPs are able to highly reduce $\alpha$ - and $\beta$-carboxylesterase activity, and the level of detoxifying enzymes is significantly down regulated during $\mathrm{BPH}$ development. Hassan et al. treated mosquitoes with salicylic acid (SA), 3,5-dinitrosalicylic acid (DNS), and AgNPs and found reduced levels of acetylcholinesterase after treatment with SA- and DNSAgNPs compared with the controls. They also found that $\alpha$ - and $\beta$-carboxylesterase activity was highly inhibited after treatment with SA- and DNS-AgNPs to 0.33 and $0.30 \mu \mathrm{M} \alpha, \beta$-naphthol/min/mg protein, respectively, compared with the controls [54].

At $72 \mathrm{~h}$ posttreatment, $\mathrm{H}_{4} \mathrm{~L}-$ and TBAPy-AgNPs significantly increased acid phosphatase activity from the control value of 0.224 to 0.869 and $1.035 \mathrm{mM} / \mathrm{mg} / \mathrm{min}$ $(p>0.05)$, respectively (Fig. 7E), while they decreased alkaline phosphatase activity from the control value of 1.751 to 0.596 and $0.426 \mathrm{mM} / \mathrm{mg} / \mathrm{min}(p>0.05)$, respectively (Fig. 7F). Acid and alkaline phosphatases play an important role in the hydrolytic cleavage of phosphoric acid esters and regulate the acid-alkali balance [55]. In addition, these enzymes are important for many significant physiological processes, such as metabolism and cellular signaling [56].

\section{AgNP accumulation in brown planthopper by TEM}

The $\mathrm{LC}_{30}$ exposure and control of $\mathrm{BPH}$ were used for TEM analysis to observe AgNP accumulation in the midgut cells of BPH adults. Figure 8A shows the microvilli structures in the midgut region of the control group. $\mathrm{H}_{4} \mathrm{~L}-$ and TBAPy-AgNP-treated BPH showed accumulation of Ag particles in the midgut cells as dark spots, indicated by yellow arrows and circles, respectively. We observed distinct localization and accumulation of AgNPs in the rough endoplasmic reticulum (ER), in addition to beneficial bacteria (Figs. 8B, C). Our results are in agreement with the findings of Yasur et al. [36], who observed the accumulation of AgNPs in the rough ER and some other cell organelles of the midgut cells of AgNP-treated Achaea janata larvae. Similarly, gold (Au) NPs accumulated in the rough ER and cell vesicles of AuNP-treated Drosophila melanogaster [57]. TEM insect images showed that the AgNPs absorbed by midgut cells localize and accumulate in the cells' organelles, which could lead to detrimental effects, including DNA damage, genotoxicity, mitochondrial dysfunction, altered cell morphology, and subsequent necrosis or apoptosis [58].

\section{Histological studies}

The $\mathrm{LC}_{50}$ exposure and control of $\mathrm{BPH}$ for $72 \mathrm{~h}$ were used for histological analysis. We found histological structure alterations in the midgut epithelial cells in treated insects (Fig. 9). The midgut area, including epithelial cells and the brush border, were significantly affected by $\mathrm{H}_{4} \mathrm{~L}-$ and TBAPy-AgNPs compared with the controls. The midgut epithelium of the controls exhibited normal cytoplasmic characteristics with a regular microvilli lining (Fig. 9A) at $40 \times$ magnification. $\mathrm{H}_{4} \mathrm{~L}$, TBAPy, $\mathrm{H}_{4} \mathrm{~L}-$ AgNPs, and TBAPy-AgNPs caused histological alterations in the midgut, such as elongation of epithelial cells protruding into the lumen and disintegration of the brush border (Figs. 9B, C). TBAPy-AgNPs partially destroyed the epithelial cells in the posterior region of the midgut (Fig. 9D). Notably, $\mathrm{H}_{4} \mathrm{~L}-\mathrm{AgNPs}$ caused severe damage in the midgut epithelial cells, with cytopathological variations, such as destruction of epithelial cells 


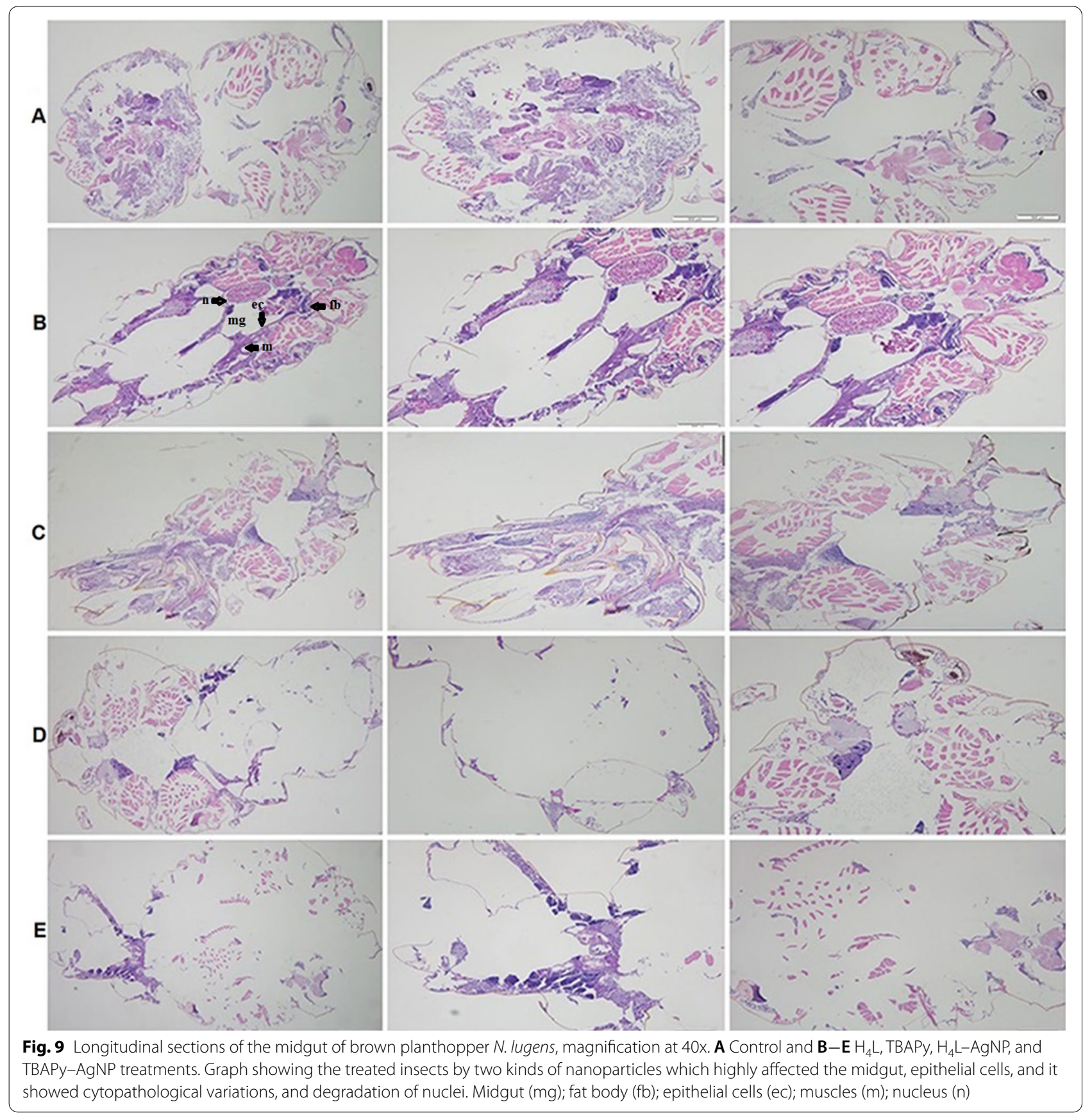

and degradation of nuclei (Fig. 9E). Severe lesions were also seen in the midgut epithelial cells, including broken membranes, brush border damage, and vacuolization (Fig. 9D, E).

\section{Conclusions}

This paper highlights AgNP synthesis via a liquid-phase reduction approach using two new alternative organic ligands $\mathrm{H}_{4} \mathrm{~L}$ and TBAPy as reducing agents, obtained by different chemical techniques. These two ligands can directly transform dissolved $\mathrm{Ag}$ ions into quasi-spherical architectures. $\mathrm{H}_{4} \mathrm{~L}-$ and TBAPy-AgNPs were used as insecticides to control the $\mathrm{BPH}$ population. At the same concentration, $\mathrm{H}_{4} \mathrm{~L}-\mathrm{AgNPs}$ are more toxic than TBAPyAgNPs after 10 days of direct contact with BPH. Furthermore, the toxicity increases with increasing doses. In addition, $\mathrm{H}_{4} \mathrm{~L}-$ and TBAPy-AgNPs significantly affect the midgut of $\mathrm{BPH}$ compared with $\mathrm{H}_{4} \mathrm{~L}$ and TBAPy alone 
and cause cytopathological variations, such as destruction of epithelial cells and degradation of nuclei. Our findings provide insights into the mechanism of action of AgNPs, which operate by affecting enzymatic pathways. AgNP-ligand formulations produce a synergetic effect to combat the adverse effects of bulk insecticide on the environment. AgNP-intercalated organic ligands present a new and potential tool for protecting rice plants from pests and may be used as an eco-friendly insecticide at low doses to reduce the $\mathrm{BPH}$ population in rice fields.

\begin{abstract}
Abbreviations
${ }^{1} \mathrm{H}$ NMR: Proton nuclear magnetic resonance; $\mathrm{AgNO}_{3}$ : Silver nitrate; AgNP: Silver nanoparticle; ANOVA: Analysis of variance; BPH: Brown planthopper; DMF Dimethylformamide; DTNB: 5,5'-Dithiobis (2-nitrobenzoic acid); EDX: Energydispersive $X$-ray spectroscopy; FT-IR: Fourier transform infrared spectroscopy; $\mathrm{H}_{4} \mathrm{~L}:$ 2'$^{\prime}$-Amino-1, 1':4', '"-terphenyl-3,3",5,5"-tetracarboxylic acid; LC 50 : Median lethal concentration; L:D: Light:day; NP: Nanoparticle; PBS: Phosphate-buffered saline; PMOF: Porous metal-organic framework; ppm: Parts per million; SBU: Secondary bonding unit; SEM: Scanning electron microscopy; SPR: Surface plasmon resonance; TBAPy: 1,3,6,8-Tetrakis ( $p$-benzoic acid)-pyrene; TEM: Transmission electron microscopy; TMS: Trimethylsilyl chloride; XRD: X-ray diffraction.
\end{abstract}

\section{Supplementary Information}

The online version contains supplementary material available at https://doi. org/10.1186/s12951-021-01068-z.

Additional file 1. Scheme S1. [1] DMF, sodium carbonate, palladium acetate, $60^{\circ} \mathrm{C}$; [II] Extracted with ethyl acetate, Synthesis of 2'-Amino-1,1 $1^{\prime}: 4^{\prime}, 1^{\prime \prime}$ terphenyl-3,3",5,5"-tetracarboxylic acid $\left(\mathrm{H}_{4} \mathrm{~L}\right)$. Scheme S2. Bromination and synthesis of 1,3,6,8-tetrakis ( $p$-benzoic acid)pyrene (TBAPy). Figure S1. 'H NMR, for the 2'-amino-1,1':4', 1"-terphenyl-3,3",5,5"-tetracarboxylate. Figure S2. ${ }^{1} \mathrm{H}$ NMR, for the 1,3,6,8-tetrakis (4-(methoxycarbonyl)phenyl)pyrene. Figure S3. ${ }^{1} \mathrm{H}$ NMR, for the 1,3,6,8-tetrakis ( $p$-benzoic acid)-pyrene. Figure S4. TEM images of the as-prepared $\mathrm{H}_{4} \mathrm{~L}-$-AgNPs complexes with different $\mathrm{AgNO}_{3}$ concentrations. (A) $1 \mathrm{mmol}$, (B) $3 \mathrm{mmol}$, and (D) $5 \mathrm{mmol}$. Figure S5. (A, B) SEM image and elemental mappings of the as-obtained $\mathrm{H}_{4} \mathrm{~L}-\mathrm{AgNPs}$ illustrating the composition of the final product and the corresponding distribution of the observed $\mathrm{Ag}(\mathbf{C}), \mathrm{Al}(\mathbf{D}), \mathrm{Cl}(\mathbf{E}), \mathrm{S}(\mathbf{F})$, and $\mathrm{O}(\mathbf{G})$ components. (H) Plots of intensity versus the cross-sectional compositional line of the complex. Figure S6. EDX patterns of synthesized silver nanoparticles (A) $\mathrm{H}_{4} \mathrm{~L}$-AgNPs and (B) TBAPy-AgNPs. Figure S7. Physico-chemical characterization of the nanoparticles. A and B: DLS profiles of the size distribution of $\mathrm{H}_{4} \mathrm{~L}-\mathrm{AgNP}$ and TBAPy-AgNP. C and D: Stability evaluation of Zeta potential analysis of $\mathrm{H}_{4} \mathrm{~L}-\mathrm{AgNP}$ and TBAPyAgNP. Figure S8. Graph showing the mortality \% of brown planthopper adults (A) $\mathrm{H}_{4} \mathrm{~L}$ and TBAPy solution at 500, 1000, 1500, $2000 \mathrm{mg} / \mathrm{L}$; (B) silver nanoparticles at 5, 10,15,20 mg/L; The mortality data for DMSO or control treatments were less than $10 \%$. Different letters above the bars of each figure indicate significant differences based on Duncan's test at $p \geq 0.05$ between concentrations (mg/L) and different days. Each bar represents the mean \pm SE of four replicates.

\section{Acknowledgements}

Not applicable.

\section{Authors' contributions}

Conceptualization, HF; methodology, HF and AAELS; validation, HF; formal analysis, $\mathrm{HF}$ and $\mathrm{GY}$; investigation, JM and HF; writing-original draft preparation, $\mathrm{HF}, \mathrm{GM}, \mathrm{DKH}$ and $\mathrm{El}$; writing-review and editing, $\mathrm{HF}, \mathrm{HG}$ and MS; visualization, HF and JM; supervision, JM. All authors read and approved the final manuscript.

\section{Funding}

We are grateful to financial support by the National Natural Science Foundation of China (Research fund for international young scientists) [Grant Number 32050410291], National Natural Science Foundation of China [Grant Number 31770686], and the Special Fund for Agro-scientific Research through a major research project [Grant Number 201403030].

\section{Availability of data and materials}

The datasets used and/or analysed during the current study are available from the corresponding author on reasonable request.

\section{Declarations}

Ethics approval and consent to participate

All applicable international, national, and/or institutional guidelines for the care and use of animals were followed.

\section{Consent for publication}

Not applicable.

\section{Competing interests}

The authors declare that they have no competing interests.

\section{Author details}

${ }^{1}$ Ministry of Agriculture, Key Laboratory of Molecular Biology of Crop Pathogens and Insect Pests, Key Laboratory of Biology of Crop Pathogens and Insects of Zhejiang Province, Institute of Insect Sciences, College of Agriculture and Biotechnology, Zhejiang University, Yuhangtang Road 866, Hangzhou, Zhejiang 310058, People's Republic of China. ${ }^{2}$ Department of Field Crop Pests, Plant Protection Research Institute, Agricultural Research Centre 12622, Dokki, Cairo, Egypt. ${ }^{3}$ Photochemistry Department, National Research Center, Dokki, Giza, Egypt. ${ }^{4}$ State Key Laboratory of Silicon Material, School of Materials Science and Engineering, Zhejiang University, Hangzhou, China. ${ }^{5}$ State Key Laboratory of Rice Biology and Ministry of Agriculture Key Lab of Molecular Biology of Crop Pathogens and Insects, Institute of Biotechnology, Zhejiang University, Hangzhou 310058, China.

Received: 21 July 2021 Accepted: 30 September 2021

Published online: 13 October 2021

\section{References}

1. Ahmad T, Wani IA, Manzoor N, Ahmed J, Asiri AM. Biosynthesis, structural characterization and antimicrobial activity of gold and silver nanoparticles. Colloids Surf, B. 2013;107:227-34.

2. Kaushik R, Mann A, Sandhu B, Parihar V. Green synthesis of gold nanoparticles using Toona ciliata methanol bark extract and their characterization. Int Res J Pharm. 2012;3:115-9.

3. Thangavel S, Ramaraj R. Polymer membrane stabilized gold nanostructures modified electrode and its application in nitric oxide detection. J Phys Chem C. 2008;112:19825-30.

4. Nasrollahzadeh M, Sajjadi M, Iravani S, Varma RS. Green-synthesized nanocatalysts and nanomaterials for water treatment: current challenges and future perspectives. J Hazardous Mater. 2020;123:401.

5. Khlebtsov N, Dykman L. Biodistribution and toxicity of gold nanoparticles. Nanotechnol Russ. 2011:6:17-42.

6. Kamali M, Dewil R, Appels L, Aminabhavi TM. Nanostructured materials via green sonochemical routes-sustainability aspects. Chemosphere. 2021;276:130146

7. Lin N, Huang J, Dufresne A. Preparation, properties and applications of polysaccharide nanocrystals in advanced functional nanomaterials: a review. Nanoscale. 2012;4:3274-94.

8. Su C. Environmental implications and applications of engineered nanoscale magnetite and its hybrid nanocomposites: A review of recent literature. J Hazard Mater. 2017;322:48-84.

9. Dhanasekaran D, Thangaraj R. Evaluation of larvicidal activity of biogenic nanoparticles against filariasis causing Culex mosquito vector. Asian Pac J Trop Dis. 2013;3:174-9. 
10. Moulton MC, Braydich-Stolle LK, Nadagouda MN, Kunzelman S, Hussain SM, Varma RS. Synthesis, characterization and biocompatibility of "green" synthesized silver nanoparticles using tea polyphenols. Nanoscale. 2010;2:763-70.

11. Fouad H, Hongjie L, Yanmei D, Baoting Y, El-Shakh A, Abbas G, et al. Synthesis and characterization of silver nanoparticles using Bacillus amyloliquefaciens and Bacillus subtilis to control filarial vector Culex pipiens pallens and its antimicrobial activity. Artif Cells Nanomed Biotechnol. 2016;9:1-10.

12. Shafi A, Bano S, Khan N, Sultana S, Rehman Z, Rahman MM, et al. Nanoremediation technologies for sustainable remediation of contaminated environments: Recent advances and challenges. Chemosphere. 2021:9776:130065.

13. Dupo ALB, Barrion AT. Taxonomy and general biology of delphacid planthoppers in rice agroecosystems Planthoppers: new threats to the sustainability of intensive rice production systems in Asia Los Baños (Philippines). Los Baños: International Rice Research Institute; 2009. p. 3-156.

14. Pathak MD, Khan ZR. Insect pests of rice. Los Baños: International Rice Research Institute; 1994

15. Zhang X, Liu X, Zhu F, Li J, You H, Lu P. Field evolution of insecticide resistance in the brown planthopper (Nilaparvata lugens Stål) in China. Crop Prot. 2014;58:61-6.

16. Ling $Y$, Huang $F$, Long $L$, Zhong $Y$, Yin W, Huang $S$, et al. Studies on the pesticide resistant of Nilaparvata lugens (Stål) in China and Vietnam. Chinese Journal of Applied Entomology. 2011;48:1374-80.

17. Wang $P$, Ning Z, Zhang S, Jiang T, Tan L, Dong S, et al. Resistance monitoring to conventional insecticides in brown planthopper, Nilaparvata lugens (Hemiptera: Delphacidae) in main rice growing regions in China. Chin J Rice Sci. 2013;27:191-7.

18. Wang Y-H, Wang Q, Shen J-L, Wu S-G, Yu R-X, Zhao X-P, et al. Current status of insecticide resistance in the brown planthopper Nilaparvata lugens. Chin Bull Entomol. 2009;4:005.

19. Santhosh SB, Ragavendran C, Natarajan D. Spectral and HRTEM analyses of Annona muricata leaf extract mediated silver nanoparticles and its larvicidal efficacy against three mosquito vectors Anopheles stephensi, Culex quinquefasciatus, and Aedes aegypti. J Photochem Photobiol, B. 2015;153:184-90.

20. Bahrulolum H, Nooraei S, Javanshir N, Tarrahimofrad H, Mirbagheri VS, Easton $\mathrm{AJ}$, et al. Green synthesis of metal nanoparticles using microorganisms and their application in the agrifood sector. J Nanobiotechnol. 2021;19:86.

21. Bharadwaj PK, Feng P, Kaskel S, Xu Q. Metal-organic frameworks and their applications. Berlin: Wiley Online Library; 2019.

22. Venkataramana G, Sankararaman S. Synthesis, absorption, and fluorescenceemission properties of 1, 3, 6, 8-tetraethynylpyrene and its derivatives. Eur J Org Chem. 2005;2005:4162-6.

23. Ebata K, Masuko M, Ohtani H, Kashiwasake-Jibu M. Nucleic acid hybridization accompanied with excimer formation from two pyrene-labeled probes. Photochem Photobiol. 1995;62:836-9.

24. Lakowicz JR, Masters BR. Principles of fluorescence spectroscopy. J Biomed Optics. 2008;13:029901.

25. Rimoldi M, Nakamura A, Vermeulen NA, Henkelis JJ, Blackburn AK, Hupp JT, et al. A metal-organic framework immobilised iridium pincer complex. Chem Sci. 2016:7:4980-4.

26. Sun Y-P, Li X, Cao J, Zhang W, Wang HP. Characterization of zero-valent iron nanoparticles. Adv Colloid Interface Sci. 2006;120:47-56.

27. Sassaroli M, Ruonala M, Virtanen J, Vauhkonen M, Somerharju P. Transversal distribution of acy-linked pyrene moieties in liquid-crystalline phosphatidylcholine bilayers A fluorescence quenching study. Biochemistry. 1995;34:8843-51.

28. Ladokhin AS. Distribution analysis of depth-dependent fluorescence quenching in membranes: a practical guide. Methods Enzymol. 1997;278:462-73.

29. Amooaghaie R, Saeri MR, Azizi M. Synthesis, characterization and biocompatibility of silver nanoparticles synthesized from Nigella sativa leaf extract in comparison with chemical silver nanoparticles. Ecotoxicol Environ Saf. 2015;120:400-8.

30. Das J, Das MP, Velusamy P. Sesbania grandiflora leaf extract mediated green synthesis of antibacterial silver nanoparticles against selected human pathogens. Spectrochim Acta Part A Mol Biomol Spectrosc. 2013;104:265-70.

31. Subhashini M, Ravindranath M. Haemolymph protein concentration of Scylla serrata: assessment of quantitative methods and intra-individual variability. Arch Int Physiol Biochim. 1980;88:47-51.
32. Lowry OH, Rosebrough NJ, Farr AL, Randall RJ. Protein measurement with the Folin phenol reagent. J biol Chem. 1951;193:265-75.

33. Ikezawa H, Taguchi R. Phosphatidylinositol-specific phospholipase C from Bacillus cereus and Bacillus thurinǵiensis Methods in enzymology. Berlin: Elsevier; 1981. p. 731-41.

34. Asparen KV. A study of housefly esterase by means of a sensitive colorimetric method. J Insect Physiol. 1962;8:401-16.

35. Asakura K. Phosphatase activity in the larva of the euryhaline mosquito, Aedes togoi Theobald, with special reference to sea-water adaptation. J Exp Mar Biol Ecol. 1978;31:325-37.

36. Yasur J, Rani PU. Lepidopteran insect susceptibility to silver nanoparticles and measurement of changes in their growth, development and physiology. Chemosphere. 2015;124:92-102.

37. Kjanijou M, Jiraungkoorskul K, Kosai P, Jiraungkoorskul W. Effect of Murraya paniculata leaf extract against Culex quinquefasciatus larva. Asian Journal of Biological Sciences. 2012;5:201-8.

38. Finney D. Probit Analysis. 3rd ed. London: Cambridge University Press; 1971.

39. De D, Pal TK, Neogi S, Senthilkumar S, Das D, Gupta SS, et al. A versatile Cull metal-organic framework exhibiting high gas storage capacity with selectivity for $\mathrm{CO}_{2}$ : conversion of $\mathrm{CO}_{2}$ to cyclic carbonate and other catalytic abilities. Chem Eur J. 2016;22:3387-96.

40. Mondloch JE, Bury W, Fairen-Jimenez D, Kwon S, DeMarco EJ, Weston MH, et al. Vapor-phase metalation by atomic layer deposition in a metal-organic framework. J Am Chem Soc. 2013;135:10294-7.

41. LiT, Kozlowski MT, Doud EA, Blakely MN, Rosi NL. Stepwise ligand exchange for the preparation of a family of mesoporous MOFs. J Am Chem Soc. 2013;135:11688-91.

42. Wang C, Kim YJ, Singh P, Mathiyalagan R, Jin Y, Yang DC. Green synthesis of silver nanoparticles by Bacillus methylotrophicus, and their antimicrobial activity. Artif Cells Nanomed Biotechnol. 2016;44:1127-32.

43. Solairaj D, Rameshthangam P. Silver nanoparticle embedded a-chitin nanocomposite for enhanced antimicrobial and mosquito larvicidal activity. J Polym Environ. 2019;9:1-18.

44. Ihegwuagu NE, Sha'Ato R, Tor-Anyiin TA, Nnamonu LA, Buekes P, Sone B, et al. Facile formulation of starch-silver-nanoparticle encapsulated dichlorvos and chlorpyrifos for enhanced insecticide delivery. New J Chem. 2016:40:1777-84.

45. Jha AK, Prasad K, Kumar V, Prasad K. Biosynthesis of silver nanoparticles using Eclipta leaf. Biotechnol Prog. 2009;25:1476-9.

46. Chandhirasekar K, Thendralmanikandan A, Thangavelu P, Nguyen B-S, Nguyen T-A, Sivashanmugan K, et al. Plant-extract-assisted green synthesis and its larvicidal activities of silver nanoparticles using leaf extract of Citrus medica, Tagetes lemmonii, and Tarenna asiatica. Mater Lett. 2021;287:129265.

47. Sowndarya P, Ramkumar G, Shivakumar M. Green synthesis of selenium nanoparticles conjugated Clausena dentata plant leaf extract and their insecticidal potential against mosquito vectors. Artif Cells Nanomed Biotechnol. 2016;9:1-6.

48. Badawy AME, Luxton TP, Silva RG, Scheckel KG, Suidan MT, Tolaymat TM. Impact of environmental conditions ( $\mathrm{pH}$, ionic strength, and electrolyte type) on the surface charge and aggregation of silver nanoparticles suspensions. Environ Sci Technol. 2010;44:1260-6.

49. Wijnhoven SW, Peijnenburg WJ, Herberts CA, Hagens WI, Oomen AG, Heugens EH, et al. Nano-silver a review of available data and knowledge gaps in human and environmental risk assessment. Nanotoxicology. 2009;3:109-38.

50. Suryawanshi RK, Patil CD, Borase HP, Narkhede CP, Salunke BK, Patil SV. Mosquito larvicidal and pupaecidal potential of prodigiosin from Serratia marcescens and understanding its mechanism of action. Pestic Biochem Physiol. 2015;123:49-55.

51. Guilger-Casagrande M, Germano-Costa T, Bilesky-José N, Pasquoto-Stigliani T, Carvalho L, Fraceto LF, et al. Influence of the capping of biogenic silver nanoparticles on their toxicity and mechanism of action towards Sclerotinia sclerotiorum. J Nanobiotechnol. 2021;19:1-18.

52. Govindarajan M, Rajeswary M, Veerakumar K, Muthukumaran U, Hoti S, Benelli G. Green synthesis and characterization of silver nanoparticles fabricated using Anisomeles indica: mosquitocidal potential against malaria, dengue and Japanese encephalitis vectors. Exp Parasitol. 2016;161:40-7.

53. Brogdon WG, MCAllister JC. Insecticide resistance and vector control. Emerg Infect Dis. 1998;4:605. 
54. Ga'al H, Fouad H, Tian J, Hu Y, Abbas G, Mo J. Synthesis, characterization and efficacy of silver nanoparticles against Aedes albopictus larvae and pupae. Pestic Biochem Physiol. 2018;144:49-56.

55. Walter K, Schutt C. Methods of enzymatic analysis. New York: Academic. 1974;2:856-64.

56. Nathan SS, Choi M-Y, Paik C-H, Seo H-Y. Food consumption, utilization, and detoxification enzyme activity of the rice leaffolder larvae after treatment with Dysoxylum triterpenes. Pestic Biochem Physiol. 2007;88:260-7.

57. Pompa PP, Vecchio G, Galeone A, Brunetti V, Sabella S, Maiorano G, et al. In vivo toxicity assessment of gold nanoparticles in Drosophila melanogaster. Nano Res. 2011;4:405-13.
58. Zhang T, Wang L, Chen Q, Chen C. Cytotoxic potential of silver nanoparticles. Yonsei Med J. 2014;55:283-91.

\section{Publisher's Note}

Springer Nature remains neutral with regard to jurisdictional claims in published maps and institutional affiliations.
Ready to submit your research? Choose BMC and benefit from:

- fast, convenient online submission

- thorough peer review by experienced researchers in your field

- rapid publication on acceptance

- support for research data, including large and complex data types

- gold Open Access which fosters wider collaboration and increased citations

- maximum visibility for your research: over 100M website views per year

At BMC, research is always in progress.

Learn more biomedcentral.com/submissions 